\title{
Mid and Near-Infrared Reflection Spectral Database of Natural Organic Materials in the Cultural Heritage Field
}

\author{
Claudia Invernizzi, ${ }^{1,2}$ Tommaso Rovetta, ${ }^{1,3}$ Maurizio Licchelli, ${ }^{1,4}$ and Marco Malagodi ${ }^{10,5}$ \\ ${ }^{1}$ Arvedi Laboratory of Non-Invasive Diagnostics, CISRiC, University of Pavia, Via Bell'Aspa 3, 26100 Cremona, Italy \\ ${ }^{2}$ Department of Mathematical, Physical and Computer Sciences, University of Parma, Parco Area delle Scienze, 7/A, \\ 43124 Parma, Italy \\ ${ }^{3}$ Department of Physics, University of Pavia, Via Bassi 6, 27100 Pavia, Italy \\ ${ }^{4}$ Department of Chemistry, University of Pavia, via Taramelli 12, 27100 Pavia, Italy \\ ${ }^{5}$ Department of Musicology and Cultural Heritage, University of Pavia, Corso Garibaldi 178, 26100 Cremona, Italy
}

Correspondence should be addressed to Marco Malagodi; marco.malagodi@unipv.it

Received 29 May 2018; Accepted 4 September 2018; Published 1 October 2018

Academic Editor: David Touboul

Copyright ( 2018 Claudia Invernizzi et al. This is an open access article distributed under the Creative Commons Attribution License, which permits unrestricted use, distribution, and reproduction in any medium, provided the original work is properly cited.

\begin{abstract}
This study presents mid and near-infrared $\left(7500-375 \mathrm{~cm}^{-1}\right)$ total reflection mode spectra of several natural organic materials used in artworks as binding media, consolidants, adhesives, or protective coatings. A novel approach to describe and interpret reflectance bands as well as calculated absorbance after Kramers-Kronig transformation (KKT) is proposed. Transflection mode spectra have represented a valuable support both to study the distorted reflectance bands and to validate the applicability and usefulness of the KK correction. The aim of this paper is to make available to scientists and conservators a comprehensive infrared reflection spectral database, together with its detailed interpretation, as a tool for the noninvasive identification of proteins, lipids, polysaccharides, and resins by means of portable noncontact FTIR spectrometers.
\end{abstract}

\section{Introduction}

For about ten years, modern heritage science community has been moving toward the development of nondestructive and noninvasive diagnostic methodologies that do not require any removal of small fragments from precious or unique works of art and preferably enable in situ investigations [14]. Furthermore, the omission of invasive sampling makes the measurements repeatable at any time, thus allowing the potential monitoring of materials conservation state over the years and the overcoming of the limit of poor representativity typical of microdestructive analyses [5].

Fourier transform infrared spectroscopy (FTIR) is one of the most important analytical techniques for the identification of organic and inorganic chemical compounds on the basis of the functional group characterization. Until recently, infrared spectroscopy applied to the study of Cultural Heritage artefacts has been mainly used in either transmission, attenuated total reflection (ATR) or diffuse reflection (DRIFT) modes [6-8]. These techniques are very accurate and precise, giving a truthful characterization of the single specimen, at the expense of the need for sampling or the contact with the surface. In order to gradually reduce the use of sampling methods to the benefit of the artwork integrity, the last decades have seen an increasing use of noninvasive infrared reflection techniques thanks to the development in the infrared instrumentation technology. Portable noninvasive FTIR spectrophotometers work in total reflection mode by means of fiber optics [9-11] or, just more recently, reflection mode accessories [12-14]. Yet the main drawback is related to the interpretation of the reflectance spectral data, which can present large distortions of band shape, absorption frequency, and intensity compared to transmittance spectra. These anomalies are due to several factors, such as absorption $(k)$ and refraction $(n)$ indices and surface roughness, which affect the extent of specular 
(or surface) and diffuse (or volume) reflection contributions. In particular, the specular component is ruled by Fresnel's law giving rise to first-derivative-like spectral bands from materials with $k<1$ and/or to Reststrahlen (or inverted) bands when $k \gg 1$, while the diffuse component appears as features that are very similar to those collected in transmission mode except for some differences in terms of relative band intensities $[6,15]$. It is worth reporting that the application of specific data-processing algorithms, such as the KramersKronig transformation (KKT), can give accurate and reliable results on condition that specific required conditions are correctly fulfilled [16-18].

As regards natural organic materials composing the art objects, existing mid-infrared (MIR) reflection studies are limited to their interaction, as binding media, with inorganic pigments $[9,19,20]$ or to very specific fields of interest [21]. A valuable reflectance spectral database in the nearinfrared (NIR) region has been set up [1]. In order to correctly interpret infrared reflection spectra of natural organic components in the expanded region of MIR and a portion of NIR, we considered the building of a reflectance spectral database as mandatory. This necessity is mainly due to the fact that reflection spectra cannot be generally identified using the available archives of spectral signatures acquired in transmission or ATR modes.

The paper here presented aims to fill this gap, by providing a detailed interpretation of $\mathrm{mid}\left(4000-375 \mathrm{~cm}^{-1}\right)$ and near $\left(7500-4000 \mathrm{~cm}^{-1}\right)$ infrared total reflection mode spectra of sixteen pure, nonaged natural organic compounds used in artworks as binding media, consolidants, adhesives or protective coatings. Firstly, a description of midIR absorption bands acquired in transflection mode (TR) was given. In TR spectrometry, the beam is transmitted through a surface film, whose thickness must be on the order of one-half wavelength or more, and reflected from a metallic surface. Following these conditions, the collected spectrum is quite similar to the transmission spectrum of the material and the bands are considered absorption ones. These data represented a crucial starting point for the study and the interpretation of the distorted total reflectance spectral behavior in the MIR region, as well as having made available an accurate, direct visual comparison in frequency and lineshape between absorption and reflection bands. TR spectra were then used to assess the applicability and usefulness of the Kramers-Kronig correction for an easier interpretation of reflectance bands. For the sake of completeness, the interpretation of reflection spectral signals in the restricted portion of NIR region was given, as added value for the identification of the substances. Final output of this work is to provide a comprehensive database of FTIR reflectance spectra to scientists and conservators as a tool for the noninvasive identification of natural organic materials belonging to the classes of proteins, lipids, polysaccharides, and resins. In conclusion, it is worth emphasizing that the paper represents a fundamental, preliminary study for tackling the subsequent interpretation of the more complex mixtures, layered systems or aged materials occurring in real cases.

\section{Materials and Methods}

2.1. Reference Materials. Sixteen commercially available materials (Kremer Pigmente GmbH \& Co., Aichstetten, Germany) were selected according to their widespread use in art. The reference compounds belong to the classes of polysaccharide (cellulose 63600; Arabic gum 63300), lipid (carnauba wax 62300; beeswax 62200; shellac wax 60550), proteinaceous (hide glue 63020; bone glue 63000; casein 63200) and natural resinous (sandarac 60100; manila copal 60150; colophony 60310; Venetian turpentine 62010; dammar 60001; mastic 60050; shellac 60480; dragon's blood 37000) materials.

2.2. Sample Preparation. In order to prepare the samples for the infrared analyses, each substance was dissolved in a proper solvent $(20 \% \mathrm{w} / \mathrm{v})$ : distilled water for animal glues, cellulose and Arabic gum, ammonium hydroxide for casein, and absolute ethanol for all resins with the exception of Venetian turpentine for which 1-propanol was required. The solutions were then purified using a polyethylene filter funnel (stitch size of $60 \mu \mathrm{m}$ ). Waxes were simply heated in water bath until reaching the melting point $\left(60-90^{\circ} \mathrm{C}\right)$. With the aim of collecting mainly the specular component and minimizing the diffuse one in the total reflection analysis, bulk samples with flat surface were prepared using the procedure described in a preliminary paper [23]. To compare and prove the accuracy of the method, transflection mode spectra were acquired from a thin film laid on a smooth reflective substrate (i.e., aluminum foil).

2.3. Portable FTIR Reflectance Spectroscopy. Both total reflection and transflection mode FTIR spectra were recorded using the Alpha portable spectrometer (Bruker Optics, Germany/USA-MA) equipped with a SiC globar source, a permanently aligned RockSolid interferometer (with gold mirrors) and a DLaTGS detector. Measurements were performed at a working distance of $15 \mathrm{~mm}$ by an external reflectance module with an optical layout of $23^{\circ} / 23^{\circ}$. Pseudoabsorbance spectra $[\log (1 / \mathrm{R}) ; \mathrm{R}=$ reflectance $]$ were acquired between 7500 and $375 \mathrm{~cm}^{-1}$ from areas of about $5 \mathrm{~mm}$ in diameter, at a resolution of $4 \mathrm{~cm}^{-1}$ and with an acquisition time of $1 \mathrm{~min}$. Spectra from a gold flat mirror were used as background. An average of three spectra for each sample was carried out. Mid-infrared total reflection mode spectra were transformed to absorbance spectra by applying the Kramers-Kronig algorithm (included in the OPUS 7.2 software package). A large negative band can appear in the corrected reflection spectra around $3600 \mathrm{~cm}^{-1}$, as an artefact of KK transformation [13].

2.4. Spectral Analysis. The extent of specular reflection contribution turned out to be predominant over the mid-IR region in all acquired total reflection mode spectra resulting in a derivative-like band profile. The specular reflection bands have been discussed by the functional group giving rise to characteristic slope, maximum position and shape. These 


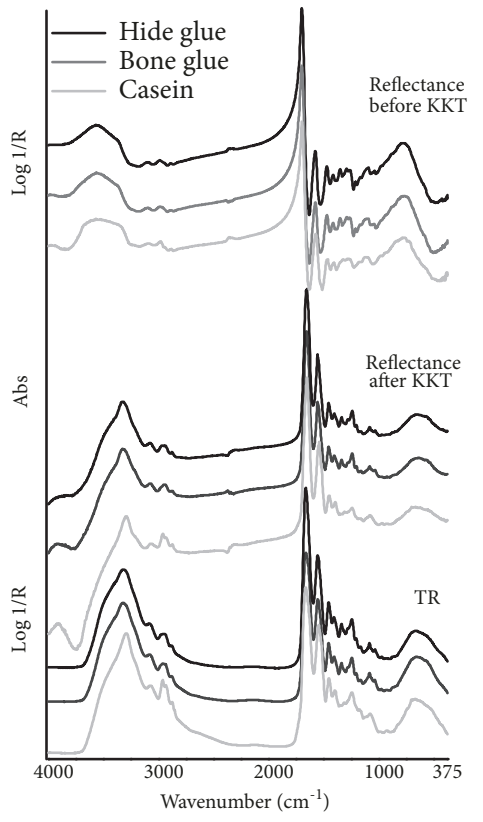

(a)

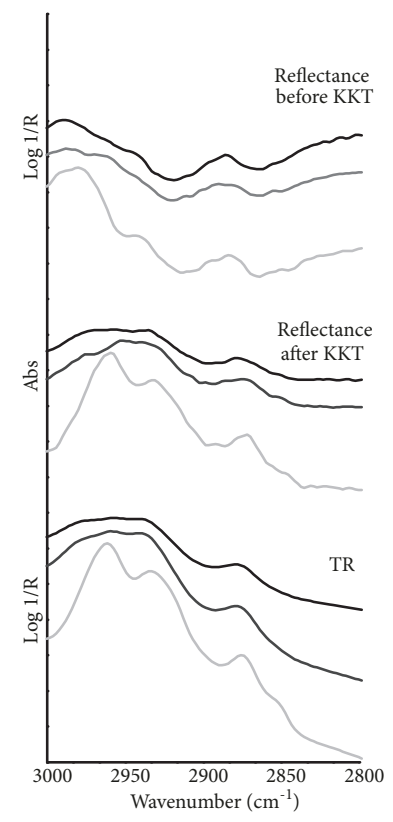

(b)

FIGURE 1: FTIR spectra in the mid-infrared region of the studied proteinaceous materials (black line: hide glue, gray line: bone glue, light gray line: casein) using different analysis modes. From top to bottom: total reflection mode before the KKT correction, total reflection mode after the KKT correction, and transflection mode. Spectral regions of (a) $4000-375 \mathrm{~cm}^{-1}$ and (b) $\mathrm{CH}$ stretching bands.

derivative-shaped bands are correlated to their corresponding KK transformed bands, which are superimposable, in turn, on the absorption signals acquired in transflection mode and whose frequency attribution is widely known by literature [24-26]. The fact that the KK corrected and TR spectra are comparable means that the required conditions for a successful Kramers-Kronig transformation have been correctly fulfilled, and confirms the specular reflection as the main collected contribute of the total reflection mode spectra in the mid-IR region. From a comparative evaluation of the collected spectra, we can see that the steeper the slope of a derivative-shaped band is the sharper the lineshape of the corresponding absorption band gets, whereas slope changes mean the presence of multiple bands. Instead, the inflection point (i.e., the point on a curve at which the concavity changes) of specular reflectance bands corresponds to the band maximum of the absorption ones. However, the difficulty often detected in determining the precise point of inflection has made it more relevant to refer to the maximum of specular reflectance bands, the wavenumber value resulting up-shifted compared to that one of absorbance bands. On the other hand, specular distortions due to the Reststrahlen effect have not appeared in the analyzed spectra, as expected by low absorption coefficient materials. As regards near-IR region, combination and overtone bands were not subjected to spectral anomalies; because of the small absorption coefficients, the diffuse contribution results, indeed the dominant factor, in determining the behavior of the NIR reflection bands $[6,27]$.

\section{Results and Discussion}

In this section, the detailed analysis of the spectra recorded in transflection and total reflection modes from the natural organic materials, grouped into four classes, will be proposed and discussed.

3.1. Proteinaceous Materials. Proteins are macromolecules made up of one or more unbranched chains of amino acids, which are joined together by peptide bonds between the carboxyl and amino groups of adjacent amino acids residues. Concerning the analyzed materials, casein is a phosphoprotein complex that is precipitated by the acidification of skimmed milk whereas animal glues are obtained by dissolving collagen, the fibrous protein of connective tissues in animals which contains three polypeptide $\alpha$-chains in a triple helix conformation. In art and art conservation, they have been mainly used as binding media, consolidants and adhesives [28] and, less frequently, in protective treatments on different material typologies (e.g., stones, fossils) [29].

In TR mode, the mid-IR spectral range of the selected proteinaceous materials is characterized by consistent recognizable absorption peaks (Figure 1(a)). A typical stairstep pattern is formed by the amide I band in the region of $1650 \mathrm{~cm}^{-1}$, due to the strong carbonyl stretching vibration $(\mathrm{C}=\mathrm{O})$, then the amide II band near $1550 \mathrm{~cm}^{-1}$ as a combination of $\mathrm{C}-\mathrm{N}$ stretching and $\mathrm{N}-\mathrm{H}$ bending vibrations and finally the $\mathrm{CH}$ bending vibration occurring near $1450 \mathrm{~cm}^{-1}$, occasionally referred to as an amide III. The asymmetrical 
$\mathrm{N}-\mathrm{H}$ stretching vibration occurring near $3300 \mathrm{~cm}^{-1}$ and the first overtone of amide II band positioned at $3080 \mathrm{~cm}^{-1}$ both appear as peaks on the broader $\mathrm{O}-\mathrm{H}$ stretching band that overlaps this region. Additionally, the methyl $\left(\mathrm{CH}_{3}\right)$ and methylene $\left(\mathrm{CH}_{2}\right)$ groups produce asymmetric stretching vibrations respectively at 2960 and $2935 \mathrm{~cm}^{-1}$ and small symmetric stretching bands respectively at 2875 and $2850 \mathrm{~cm}^{-1}$. It should be noticed that these $\mathrm{CH}$ stretching bands appear better resolved in the spectrum of casein, with $\mathrm{CH}_{3}$ groups of greater intensity than $\mathrm{CH}_{2}$ groups, whereas both bone and hide glues show $\mathrm{CH}$ asymmetric stretches as broad overlapping bands with the $\mathrm{CH}_{2}$ symmetric stretching very difficult to be discerned because of its weakness (Figure 1(b)). Other small $\mathrm{CH}$ bending vibrations are found in the 1400$1300 \mathrm{~cm}^{-1}$ region as well as several C-O vibrations occur from 1250 to $1000 \mathrm{~cm}^{-1}$.

In total reflection mode, the mid-IR collected spectra (Figure 1(a)) display an intense and narrow maximum of the amide I band at $1698 \mathrm{~cm}^{-1}$, appearing predominant over the mid-infrared range, followed with decreasing intensity by the amide II and amide III bands whose sharp maxima are positioned at 1578 and $1470 \mathrm{~cm}^{-1}$, respectively. In the $3800-3200 \mathrm{~cm}^{-1}$ region, the lineshape of the $v_{\text {as }} \mathrm{N}-\mathrm{H}$ band is characterized by a steep slope with a wide-ranging maximum near $3370 \mathrm{~cm}^{-1}$ while the $\mathrm{O}-\mathrm{H}$ vibration produces a broad band having a slight slope and an unstructured maximum near $3570 \mathrm{~cm}^{-1}$. The region comprising the overtone of the amide II band and the $\mathrm{CH}$ stretches shows low-intensity bands with the maxima placed respectively near 3095, 2985, 2945, 2885 and $2855 \mathrm{~cm}^{-1}$. As observed also in TR mode, casein slightly differs from animal glues in the $\nu \mathrm{CH}$ spectral range here resulting in a major slope and more structured maxima of the band lineshape (Figure 1(b)). Concerning the more pronounced intensity difference between the $\mathrm{CH}_{3}$ and $\mathrm{CH}_{2}$ bands in the spectrum of casein compared to animal glues, this could be ascribable to the presence in the former of a higher percentage amount of amino acids containing two methyl groups each (i.e., valine, leucine and isoleucine). Some other small differences can be detected in the lowwavenumber region from 1350 to $1000 \mathrm{~cm}^{-1}$, where lessstructured and broader $\mathrm{C}-\mathrm{O}$ and $\delta \mathrm{CH}$ band maxima characterize casein compared to animal glues. The experimental wavenumbers corresponding to the maxima of the mid-IR total reflection mode bands of proteinaceous materials and their assignment are summarized in Table 1. After applying the KK correction, an accurate match in position and shape between corrected reflectance and transflectance bands can be observed (Figure 1).

Regarding the near-IR region, all three total reflection mode spectra exhibit a similar absorption pattern (Figure 2(a)). The first overtones of the asymmetric and symmetric $\mathrm{CH}_{2}$ stretching modes occur respectively at 5900 and $5775 \mathrm{~cm}^{-1}$, whereas the combination bands $\nu(\mathrm{OH})+\delta(\mathrm{OH})$ and 1st overtone $v(\mathrm{C}-\mathrm{O})$ amide I + amide II are visible near 5160 and $4600 \mathrm{~cm}^{-1}$ respectively [1]. As expected after observing the fundamental vibrations in the mid-infrared range, casein shows slightly more defined shapes of the $v_{\mathrm{a}}\left(\mathrm{CH}_{2}\right)+\delta\left(\mathrm{CH}_{2}\right)$ and $\nu_{\mathrm{s}}\left(\mathrm{CH}_{2}\right)+\delta\left(\mathrm{CH}_{2}\right)$ combination bands
TABLE 1: Experimental wavenumber values corresponding to the maxima of the mid-IR total reflection mode bands of proteinaceous materials and their tentative assignment.

\begin{tabular}{|c|c|}
\hline $\begin{array}{l}\text { Experimental } \\
\text { wavenumbers }\left(\mathrm{cm}^{-1}\right)\end{array}$ & Band assignment \\
\hline \multicolumn{2}{|l|}{$\begin{array}{l}\text { Casein and animal } \\
\text { glues }\end{array}$} \\
\hline 3570 & $\nu \mathrm{OH}$ \\
\hline 3370 & $v_{\text {as }} \mathrm{NH}$ \\
\hline 3095 & $\begin{array}{c}\text { Overtone of combination band } \\
\delta \mathrm{NH} \text { and } \nu \mathrm{CN} \text { (amide II) }\end{array}$ \\
\hline 2985 & $v_{\text {as }} \mathrm{CH}_{3}$ \\
\hline 2945 & $v_{\mathrm{as}} \mathrm{CH}_{2}$ \\
\hline 2885 & $v_{\mathrm{s}} \mathrm{CH}_{3}$ \\
\hline 2855 & $v_{\mathrm{s}} \mathrm{CH}_{2}$ \\
\hline 1698 & $\nu \mathrm{C}=\mathrm{O}$ (amide $\mathrm{I}$ ) \\
\hline 1578 & $\begin{array}{c}\text { Combination band } \delta \mathrm{NH} \text { and } \\
\nu \mathrm{CN} \text { (amide II) }\end{array}$ \\
\hline 1470 & $\delta \mathrm{CH}$ (amide III) \\
\hline $1400-1300$ & $\delta \mathrm{CH}$ \\
\hline $1300-1000$ & $\mathrm{C}-\mathrm{O}\left(\mathrm{COO}^{-}\right)$ \\
\hline
\end{tabular}

respectively at 4375 and $4260 \mathrm{~cm}^{-1}$, if compared to animal glues. Moreover, the dairy protein exhibits more resolved bands at $4865 \mathrm{~cm}^{-1}$, due to the $\nu(\mathrm{NH})+\delta(\mathrm{NH})$ combination band, and near $4055 \mathrm{~cm}^{-1}$ which could be attributed to the $\mathrm{CH}$ functional group as a combination or overtone band [30].

3.2. Lipid Materials. The use of lipids in art objects is essentially limited to waxes and drying oils, respectively made up of nonglyceryl and glyceryl esters. However, only the physical properties of the waxes fulfilled the required sample preparation conditions for reflection analysis. Associated with long-chain nonglyceryl esters are one or more of the following: free fats or wax acids, alcohols, sterols, ketones and aliphatic hydrocarbons. These components vary greatly according to the origin of the wax, which can be vegetal (e.g., carnauba wax), animal (e.g., beeswax, shellac wax) or mineral (e.g., ceresin). Since ancient times, they have been employed in art conservation as adhesives and surface coatings, and particularly as waterproofing agents thanks to their hydrophobic properties [28].

In TR mode, the MIR spectra collected from the three waxes (Figure 3) display the characteristic sharp bands produced by the many $\mathrm{CH}_{2}$ groups: the predominant asymmetric and symmetric stretches near 2920 and $2850 \mathrm{~cm}^{-1}$, and the peak splitting of scissoring and rocking vibrations into doublets respectively at $1472 / 1462 \mathrm{~cm}^{-1}$ and $730 / 720 \mathrm{~cm}^{-1}$ which indicates the semicrystalline structure of the waxes [21, and references therein]. The $\mathrm{CH}_{3}$ methyl end groups of pure, long-chain hydrocarbons produce stretching bands near 2955 and $2905 \mathrm{~cm}^{-1}$. Ester and acid/ketone groups account for the $\mathrm{C}=\mathrm{O}$ stretching bands respectively at 1735 and $1715 \mathrm{~cm}^{-1}$, appearing as an overlapping band in the shellac wax spectrum, and for the $\mathrm{C}-\mathrm{O}$ bands in the $1172 \mathrm{~cm}^{-1}$ region. 


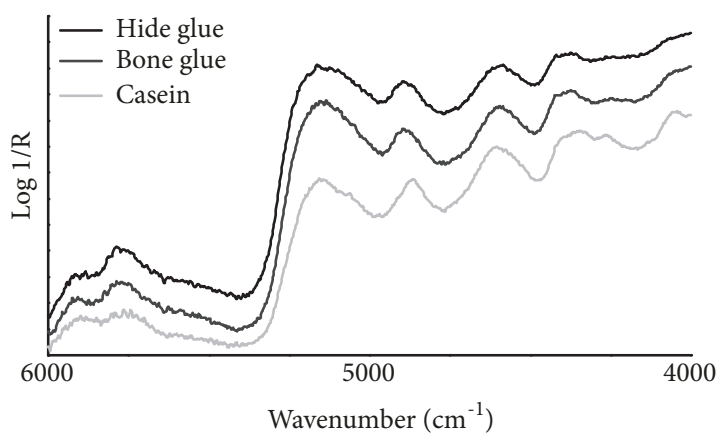

(a)

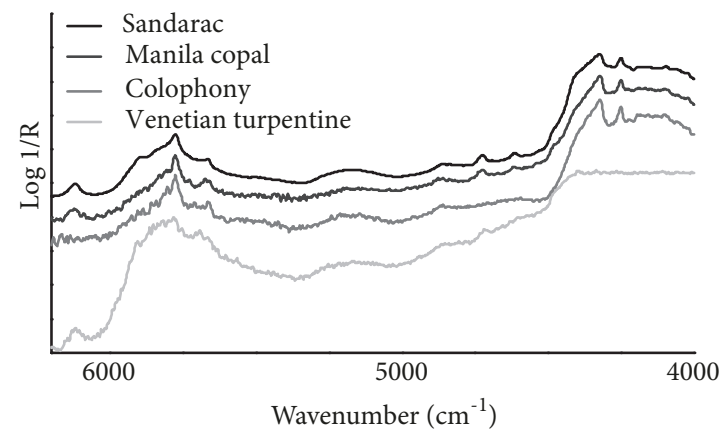

(c)

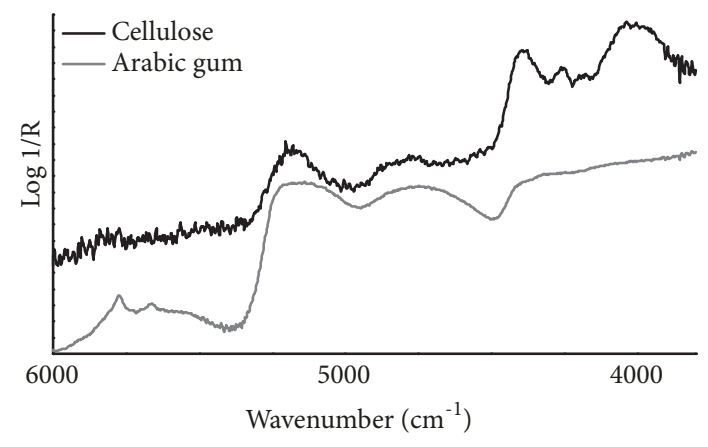

(b)

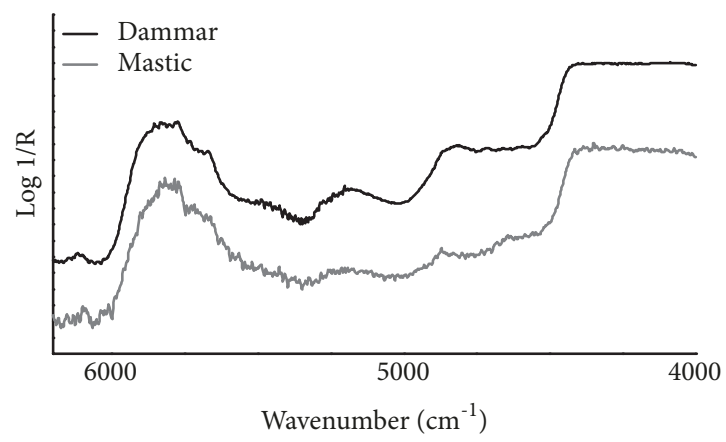

(d)

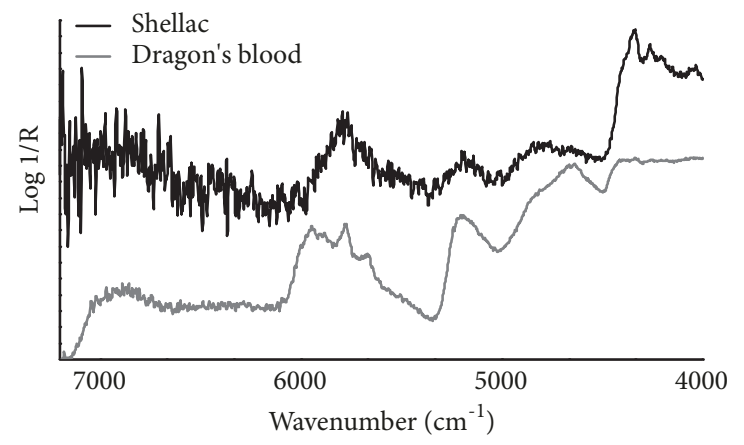

(e)

FIGURE 2: FTIR total reflection mode spectra in the near-infrared region of the studied (a) proteinaceous materials, (b) polysaccharide materials, (c) diterpenoid resins, (d) triterpenoid resins, and (e) not (exclusively) terpenoid-based resins.

Additional characteristic sharp peaks of the carnauba wax are found at $1635,1605,1515,832$ and $520 \mathrm{~cm}^{-1}$ whereas the shellac wax spectrum shows a further well-resolved band in the region of $\mathrm{C}-\mathrm{O}$ vibrations at $1240 \mathrm{~cm}^{-1}$ and a broad band near $1060 \mathrm{~cm}^{-1}$.

In total reflection mode, all acquired mid-IR spectra (Figure 3) exhibit sharp maxima of the $\mathrm{CH}_{2}$ stretching bands at 2935 and $2858 \mathrm{~cm}^{-1}$. These bands are characterized by a very steep slope of the lineshape and appear predominant over the mid-infrared range because of their intensity. The asymmetric $\mathrm{CH}_{3}$ stretching mode produces a wide and lowintensity band maximum near $2965 \mathrm{~cm}^{-1}$ while the symmetric methyl band is difficult to be discerned in these spectra. This $\nu \mathrm{CH}$ region is clearly shown in Figure 4(a). Beeswax and shellac wax spectra show two close narrow maxima both of $\mathrm{CH}_{2}$ scissoring and rocking bands respectively at 1478/1468 and $735 / 725 \mathrm{~cm}^{-1}$, corresponding to the previously described absorption doublets (Figures 4(c) and 4(d)). Conversely, the peak splitting of these bands does not appear in the spectrum of the carnauba wax and this is confirmed observing the corresponding KK corrected spectrum. The absence of these doublets is indicative of a loss of the crystal structure of hydrocarbon chains during the bulk sample preparation procedure [31]. The $\mathrm{C}=\mathrm{O}$ stretching vibrations produce a high slope ester band having the sharp maximum placed at $1745 \mathrm{~cm}^{-1}$ in the beeswax and carnauba wax spectra and at $1752 \mathrm{~cm}^{-1}$ in the spectrum of shellac wax, and a weaker acid/ketone band with the maximum respectively at 1716 and $1718 \mathrm{~cm}^{-1}$ (Figure 4(b)). Concerning this spectral region, shellac wax shows an additional well-defined narrow $\mathrm{C}=\mathrm{O}$ band (acids/ketones) with the maximum being positioned at $1735 \mathrm{~cm}^{-1}$. Another band characterized by the steep slope of 


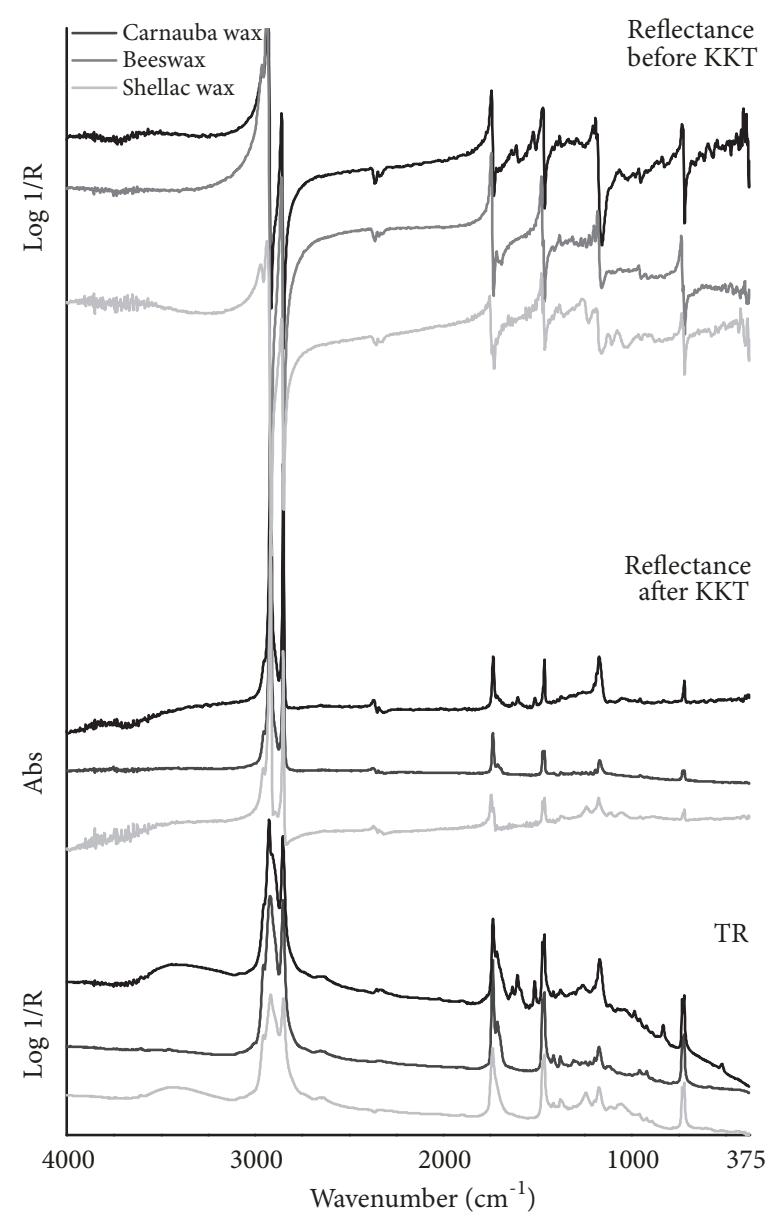

FIGURE 3: FTIR spectra in the mid-infrared region of the studied lipid materials (black line: carnauba wax, gray line: beeswax, light gray line: shellac wax) using different analysis modes. From top to bottom: total reflection mode before the KKT correction, total reflection mode after the KKT correction, and transflection mode.

the lineshape, with the maximum positioned at $1183 \mathrm{~cm}^{-1}$, is due to $\mathrm{C}-\mathrm{O}$ vibration. Those additional features detected in TR mode show the reflection maxima at 1612, 1522 and $832 \mathrm{~cm}^{-1}$ in carnauba wax and near 1250 and $1075 \mathrm{~cm}^{-1}$ in shellac wax. The experimental wavenumber values corresponding to the maxima of the mid-IR total reflection mode bands of lipid materials and their suggested assignment are summarized in Table 2.

In the NIR region, only overtones from methylenic stretching at 5770 and $5660 \mathrm{~cm}^{-1}$ can be clearly detected in total reflection mode spectra whereas combination bands from $v$ and $\delta \mathrm{CH}_{2}$ do not occur except as broad and unresolved features. It is worth noting that NIR spectra, here not shown in figure, do have a prominent noise that could make it difficult to identify the characteristic bands.

3.3. Polysaccharide Materials. Polysaccharides are polymers made up of many monosaccharide units joined together by glycoside bonds, and include cellulose, starch, honey and plant gums. As regards the analyzed materials, cellulose consists of high molecular weight polymer of D-glucose with $\beta(1-4)$-glycosidic bonds, whereas the long-chain polymers of plant gums, exudates from several species of plants or extracted from the endosperm of some seeds, are made of aldopentoses, aldohexoses and uronic acids which condense through glycosidic bonds. Arabic gum (exuded by Acacia senegal and Acacia seyal) is not only one of the most important representatives of the plant gums' family in the field of artistic and historic works, it is also of broader economic relevance and therefore produced in rather large quantities $[32,33]$. Over the time, polysaccharides have widely been used in art and art conservation as painting media and sizing agents as well as adhesives [22] and, to a lesser extent, in consolidation and protective treatments [34].

The mid-infrared TR spectra of cellulose and Arabic gum (Figure 5(a)) display the characteristic IR pattern for the polysaccharides produced by the high proportion of $\mathrm{O}-\mathrm{H}$ groups bound to the carbons. Indeed, both spectra show two strong, broad stretching bands: one in the 3400$3300 \mathrm{~cm}^{-1}$ region due to $\mathrm{O}-\mathrm{H}$ groups and the other at about $1080 \mathrm{~cm}^{-1}$ due to $\mathrm{C}-\mathrm{O}$ groups. A moderately strong band found at $1650 \mathrm{~cm}^{-1}$ in cellulose and at $1610 \mathrm{~cm}^{-1}$ in Arabic gum (with asymmetric lineshape) is partially associated with intramolecular bound water and partially due to the presence 


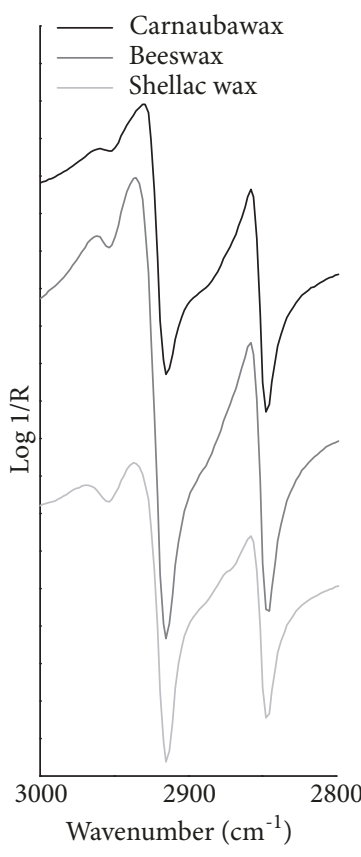

(a)

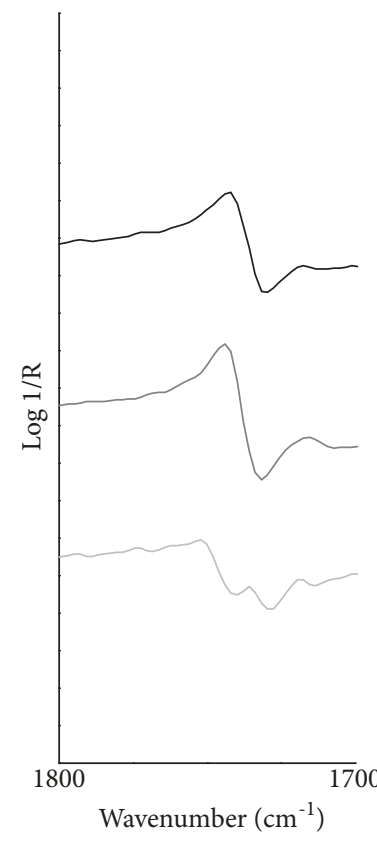

(b)

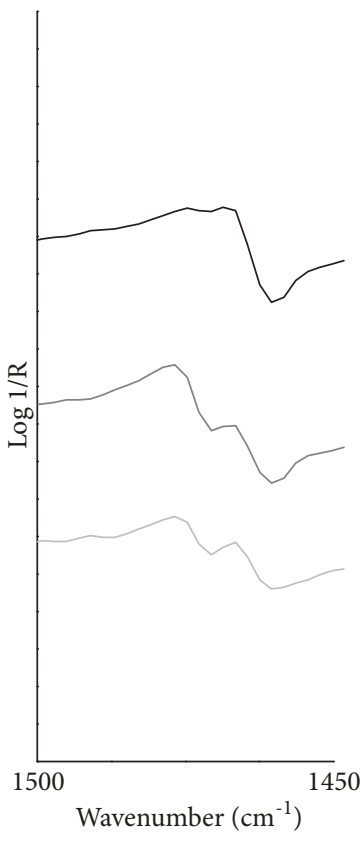

(c)

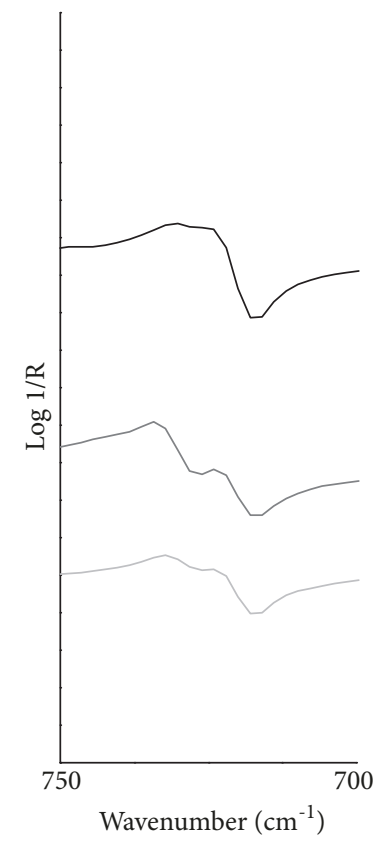

(d)

FIGURE 4: FTIR total reflection mode spectra (before the application of the KKT correction) of the studied lipid materials (black line: carnauba wax, gray line: beeswax, light gray line: shellac wax) in the regions of (a) $\mathrm{CH}$ stretching, (b) $\mathrm{C}=\mathrm{O}$ stretching, (c) $\mathrm{CH}_{2}$ scissoring, and (d) $\mathrm{CH}_{2}$ rocking.

TABLE 2: Experimental wavenumber values corresponding to the maxima of the mid-IR total reflection mode bands of lipid materials and their tentative assignment.

\begin{tabular}{lccc}
\hline \multicolumn{2}{c}{ Experimental wavenumbers $\left(\mathbf{c m}^{-1}\right)$} & Band assignment \\
\hline Beeswax & $\begin{array}{c}\text { Carnauba } \\
\text { wax }\end{array}$ & Shellac wax & \\
2965 & 2965 & 2965 & $\nu_{\text {as }} \mathrm{CH}_{3}$ \\
2935 & 2935 & 2935 & $\nu_{\text {as }} \mathrm{CH}_{2}$ \\
2858 & 2858 & 2858 & $\nu_{\mathrm{s}} \mathrm{CH}_{2}$ \\
1745 & 1745 & 1752 & $\nu \mathrm{C}=\mathrm{O}($ esters $)$ \\
& & 1735 & $\nu \mathrm{C}=\mathrm{O}$ (acids/ketones) \\
1716 & 1716 & 1718 & $\nu \mathrm{C}=\mathrm{O}$ (acids/ketones) \\
& 1612 & & \\
$1478 / 1468$ & 1522 & & $\delta_{\text {sciss }} \mathrm{CH}_{2}$ \\
& 1468 & $1478 / 1468$ & $\mathrm{C}-\mathrm{O}$ \\
1183 & 1183 & 1250 & $\mathrm{C}-\mathrm{O}$ \\
& & 1183 & \\
$735 / 725$ & 725 & $735 / 725$ & $\delta_{\text {rock }} \mathrm{CH}_{2}$ \\
\hline
\end{tabular}

of a carboxyl group, whereas the only gum spectrum presents an additional very weak, sharp peak at $1720 \mathrm{~cm}^{-1}$ which is attributed to the $\mathrm{C}=\mathrm{O}$ stretching of an ester-containing component. The lineshape of $\mathrm{CH}$ stretching and bending absorptions, respectively, found in the 3000-2800 and 1480$1300 \mathrm{~cm}^{-1}$ regions, appears sharper and more resolved in cellulose compared to Arabic gum, even though this is generally true for all spectral features. Moreover, a further well-defined peak at $950 \mathrm{~cm}^{-1}$ can be ascribed to the $\mathrm{CH}$ rocking vibration which occurs in cellulose.

In total reflection mode, the most significant region of the MIR spectra (Figure 5(a)) corresponds to the $\mathrm{C}-\mathrm{O}$ vibrations: both the polysaccharides display indeed an intense and narrow band maximum at $1171 \mathrm{~cm}^{-1}$, followed with decreasing intensity by well-defined peak maxima positioned at 1144 and $1100 \mathrm{~cm}^{-1}$ in cellulose and at 1108 in Arabic gum. The lineshape of all these combined bands is characterized by a very steep slope, thus resulting in sharp absorptions after the application of the KK logarithm. This region is more clearly shown in Figure 5(b). As regards the lower wavenumber range, the well-resolved $\mathrm{CH}$ vibration band occurring in cellulose at $958 \mathrm{~cm}^{-1}$, already highlighted at $950 \mathrm{~cm}^{-1}$ in the TR spectrum, can be considered a diagnostic feature for the distinction of the analyzed polysaccharides. The $\mathrm{O}-\mathrm{H}$ groups produce a moderately strong band which appears more marked in the gum than in cellulose: it is characterized by a broad band maximum near $3500 \mathrm{~cm}^{-1}$ and a rather slight slope of the lineshape. As already pointed out by comparison with TR spectra, the $\mathrm{CH}$ stretching and bending regions of cellulose turn out to have more resolved features compared to those of Arabic gum (for details, see Table 3), and this is also confirmed by their corresponding $\mathrm{KK}$ transformed spectra. On the contrary, the combined $\mathrm{C}=\mathrm{O}$ and $\mathrm{H}-\mathrm{O}-\mathrm{H}$ (intramolecular water) vibrations give a response which is 


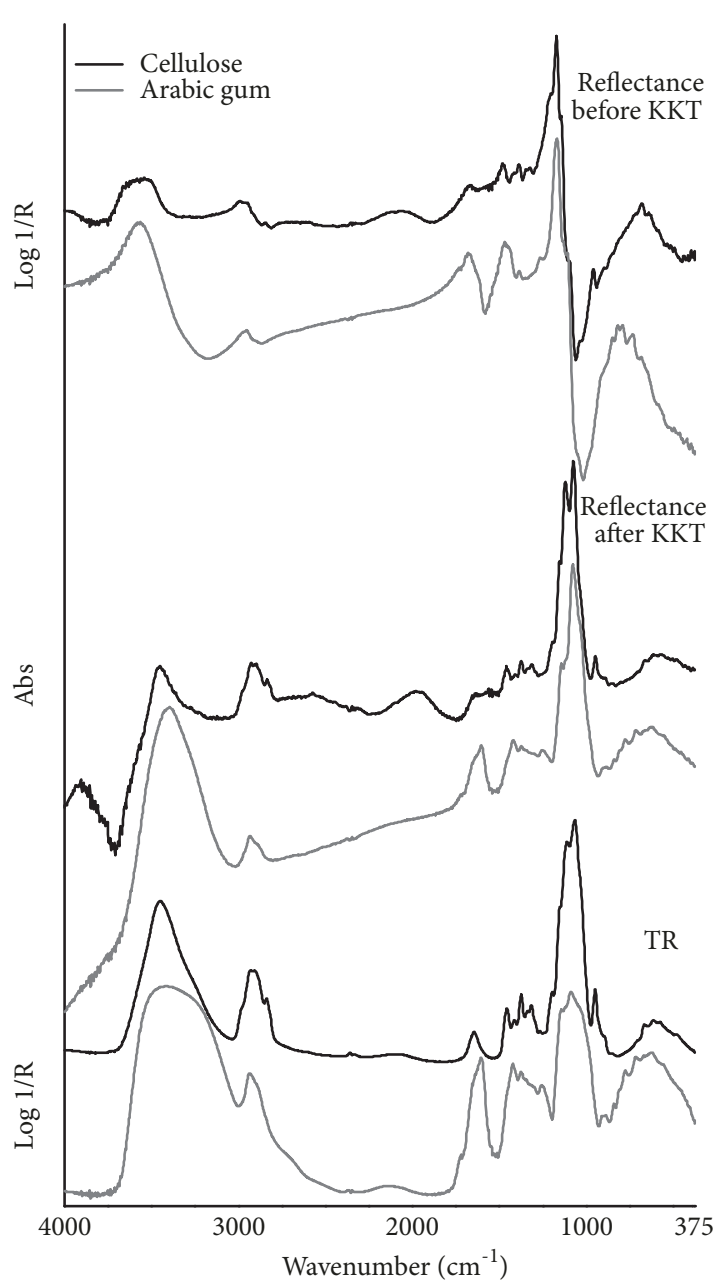

(a)

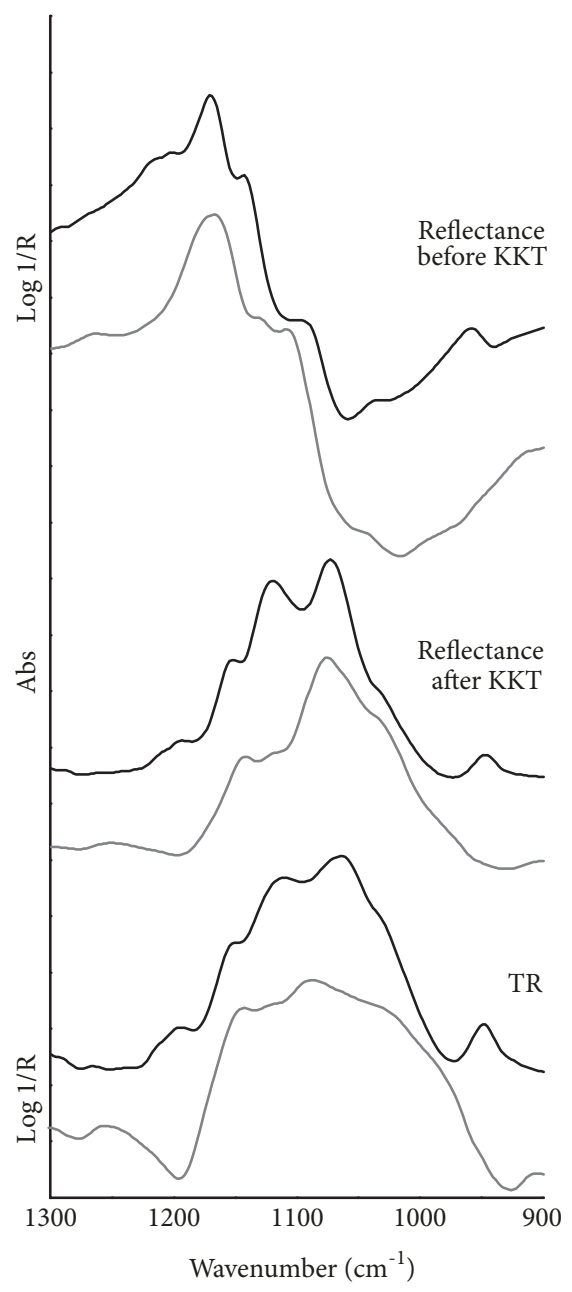

(b)

FIGURE 5: FTIR spectra in the mid-infrared region of the studied polysaccharide materials (black line: cellulose, gray line: Arabic gum) using different analysis modes. From top to bottom: total reflection mode before the KKT correction, total reflection mode after the KKT correction, and transflection mode. Spectral regions of (a) $4000-375 \mathrm{~cm}^{-1}$ and (b) C-O stretching bands.

more intense in the gum than in cellulose. Concerning this region $\left(1700-1550 \mathrm{~cm}^{-1}\right)$, the reflectance spectrum of Arabic gum displays an overlapping band characterized by two different slopes which give rise to a sharp peak at $1605 \mathrm{~cm}^{-1}$ and a shoulder near $1645 \mathrm{~cm}^{-1}$ in the corresponding KK spectrum. Furthermore, it is possible to notice that only a weak and poorly resolved feature near $1730 \mathrm{~cm}^{-1}(\mathrm{C}=\mathrm{O}$ vibration) occurs in the reflectance spectrum of Arabic gum, whereas a small sharp peak has been well distinguished using the TR technique. The detailed experimental wavenumber values corresponding to the maxima of the mid-IR total reflection mode bands, and the relative suggested assignment, are reported in Table 3.

As regards NIR region (Figure 2(b)), the investigated total reflection mode spectra are characterized by different features except for the common broad bands respectively found near $5190 \mathrm{~cm}^{-1}$, due to the combination of $\mathrm{O}-\mathrm{H}$ stretching and $\mathrm{H}-\mathrm{O}-\mathrm{H}$ bending, and near $4760 \mathrm{~cm}^{-1}$ which is attributed both to the overtone of $\mathrm{C}-\mathrm{O}$ stretching (including $\mathrm{C}=\mathrm{O}$ and $\mathrm{C}-\mathrm{O}$ ) and to the combination of $\mathrm{O}-\mathrm{H}$ bending and $\mathrm{C}$ $\mathrm{O}$ stretching. In addition to those ones, the spectrum of cellulose displays the $\mathrm{O}-\mathrm{H}$ and $\mathrm{C}-\mathrm{O}$ stretching combination band at $4400 \mathrm{~cm}^{-1}$, the overtone band of $\mathrm{CH}$ bending vibration at $4250 \mathrm{~cm}^{-1}$ with a possible further contribute of $\mathrm{CH}_{2}$ stretching and bending combination band and, finally, the combination band of $\mathrm{CH}$ and $\mathrm{C}-\mathrm{O}-\mathrm{C}$ stretches and $\mathrm{C}$ $\mathrm{C}$ vibration positioned at $4010 \mathrm{~cm}^{-1}$. On the other hand, Arabic gum exhibits the overtones bands of $\mathrm{CH}_{2}$ stretching vibrations at 5775 (asymmetric) and 5660 (symmetric) $\mathrm{cm}^{-1}$ whereas the combination bands produced by the same $\mathrm{CH}_{2}$ vibrations, which are expected to be found in the 4300$4200 \mathrm{~cm}^{-1}$ region [30], do not clearly appear.

3.4. Natural Resinous Materials. Natural resins are polymers exuded from plants or secreted by insects: although their chemistry is diverse, most are mainly composed of terpenoids, which are formally considered compounds made up of units of isoprene. Since ancient times natural resins, 
TABLE 3: Experimental wavenumber values corresponding to the maxima of the mid-IR total reflection mode bands of polysaccharide materials and their tentative assignment.

\begin{tabular}{|c|c|c|}
\hline \multicolumn{2}{|c|}{$\begin{array}{l}\text { Experimental wavenumbers } \\
\left(\mathrm{cm}^{-1}\right)\end{array}$} & \multirow[t]{2}{*}{ Band assignment } \\
\hline Cellulose & Arabic gum & \\
\hline 3510 & 3560 & $\mathrm{OH}$ \\
\hline 2985 & & $v_{\mathrm{as}} \mathrm{CH}_{3}$ \\
\hline 2950 & 2950 & $v_{\mathrm{as}} \mathrm{CH}_{2}$ \\
\hline 2918 & 2900 & $v_{\mathrm{s}} \mathrm{CH}_{3}$ \\
\hline \multirow[t]{2}{*}{2845} & & $v_{\mathrm{s}} \mathrm{CH}_{2}$ \\
\hline & 1730 & $\nu \mathrm{C}=\mathrm{O}$ (esters) \\
\hline \multirow[t]{2}{*}{1670} & 1665 & $\begin{array}{c}\mathrm{C}=\mathrm{O} \text { and } \mathrm{HOH} \\
\text { (intramolecular water) }\end{array}$ \\
\hline & 1620 & $\begin{array}{c}\mathrm{C}=\mathrm{O} \text { and } \mathrm{HOH} \\
\text { (intramolecular water) }\end{array}$ \\
\hline 1470 & 1445 & $\delta \mathrm{CH}, \nu \mathrm{C}-\mathrm{O}$ and $\delta \mathrm{COH}$ \\
\hline 1385 & 1380 & $\delta \mathrm{CH}, \nu \mathrm{C}-\mathrm{O}$ and $\delta \mathrm{COH}$ \\
\hline 1345 & & $\delta \mathrm{CH}, \nu \mathrm{C}-\mathrm{O}$ and $\delta \mathrm{COH}$ \\
\hline \multirow[t]{2}{*}{1320} & & $\delta \mathrm{CH}, \nu \mathrm{C}-\mathrm{O}$ and $\delta \mathrm{COH}$ \\
\hline & 1265 & $\delta \mathrm{CH}, \nu \mathrm{C}-\mathrm{O}$ and $\delta \mathrm{COH}$ \\
\hline 1200 & & $\nu \mathrm{C}-\mathrm{O}$ \\
\hline 1171 & 1171 & $\nu \mathrm{C}-\mathrm{O}$ \\
\hline 1144 & & $\nu \mathrm{C}-\mathrm{O}$ \\
\hline 1100 & 1108 & $\nu \mathrm{C}-\mathrm{O}$ \\
\hline 958 & & $\delta_{\text {rock }} \mathrm{CH}$ \\
\hline
\end{tabular}

alone, or in mixture with other substances, have been used extensively by artists and conservators as varnishes, consolidants, adhesives, hydrorepellents and sealing agents thanks to their intrinsic properties [22, 28]. According to their chemical composition, this section is structured into three subdivisions: diterpenoid, triterpenoid and not (exclusively) terpenoid-based resins.

Diterpenoid resins Diterpenoid resins are primarily composed of mixtures of tricyclic (abietanes and pimaranes) and dicyclic (labdanes) resin acids. The botanical origin and the chemical composition of the analyzed diterpenoid resins (i.e., colophony, Venetian turpentine, sandarac and Manila copal) are listed in Table 4 [22]. For the spectral interpretation, it is worth noting that the composition of Venetian turpentine and colophony is similar, with the former containing a remarkable amount of labdane alcohols in addition to resinous acids. As far as their composition is concerned, also sandarac and Manila copal are very similar one to the other both consisting of free diterpenoids and a highly polymerized fraction of polycommunic acid.

In TR mode, the spectra of the four diterpenoid resins show an overall similar pattern in the MIR region (Figure 6). In particular, an accurate wavenumber correspondence is observed between Venetian turpentine and colophony, on one hand, and between sandarac and Manila copal, on the other, reflecting the respective alike compositions as reported by Daher et al. [24]. All spectra are characterized

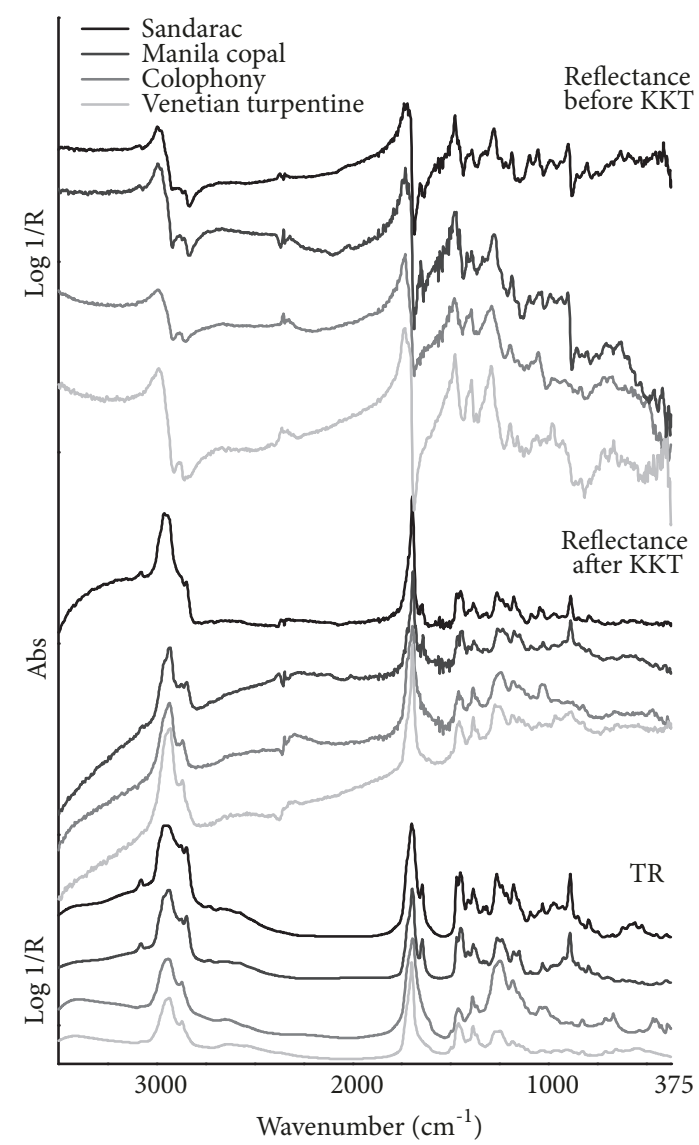

FIGURE 6: FTIR spectra in the mid-infrared region of the studied diterpenoid resins (black line: sandarac, dark gray line: Manila copal, gray line: colophony, light gray line: Venetian turpentine) using different analysis modes. From top to bottom: total reflection mode before the KKT correction, total reflection mode after the KKT correction, and transflection mode.

by intense signals in the $\mathrm{CH}$ stretching region, with an overlapping band at about $2945 \mathrm{~cm}^{-1}$ due to the asymmetric $\mathrm{CH}_{3} / \mathrm{CH}_{2}$ modes and a defined peak at $2870 \mathrm{~cm}^{-1}$ due to the symmetric $\mathrm{CH}_{3}$ mode. In addition, sandarac and Manila copal exhibit a sharp band produced by symmetric $\mathrm{CH}_{2}$ vibrations at $2850 \mathrm{~cm}^{-1}$, which suggests a considerable number of $\mathrm{CH}_{2}$ groups occurring in these resins. Broad O$\mathrm{H}$ bands are found near 3420 and $2650 \mathrm{~cm}^{-1}$, respectively due to the hydroxyl stretching absorption and to the $\mathrm{O}-\mathrm{H}$ vibration of dimerized carboxyl groups. The $\mathrm{C}=\mathrm{O}$ stretching vibration produces a characteristic sharp, strong band with the maximum falling from 1698 to $1692 \mathrm{~cm}^{-1}$. CH bending vibrations are found at about $1460 \mathrm{~cm}^{-1}$, with well-resolved features at $1468\left(\mathrm{CH}_{2}\right.$ groups) and $1450\left(\mathrm{CH}_{3}\right.$ groups) $\mathrm{cm}^{-1}$ occurring only in sandarac and Manila copal, and at $1385 \mathrm{~cm}^{-1}$ due to the symmetric $\mathrm{CH}_{3}$ mode. Moreover, several bands due both to $\mathrm{C}-\mathrm{OH}$ and $\mathrm{C}-\mathrm{O}$ groups of esters and acids and to $\mathrm{CH}_{2}$ vibrations are visible from 1300 to $900 \mathrm{~cm}^{-1}$, resulting in a more defined and well separated band lineshape for sandarac and Manila copal if compared to Venetian turpentine and colophony. Concerning this spectral 
TABLE 4: Botanical origin and chemical composition of the analyzed plant resins [22].

\begin{tabular}{|c|c|c|c|}
\hline Order & Family & Genus (type of resin) & Main composition \\
\hline \multirow[t]{4}{*}{ Coniferales } & Pinaceae & Pinus (colophony) & Abietadienic acids, pimaradienic acids \\
\hline & & Larix (Venetian turpentine) & $\begin{array}{c}\text { Abietadienic acids, pimaradienic acids, epimanool, larixol, larixyl } \\
\text { acetate }\end{array}$ \\
\hline & Araucariaceae & Agathis (Manila copal) & Sandaracopimaric acid, communic acid, agathic acid, abietic acid \\
\hline & Cupressaceae & Tetraclinis articulata (sandarac) & Pimaradienic acids (sandaracopimaric acid), communic acid, totarol \\
\hline Guttiferales & Dipterocarpaceae & Hopea (dammar) & $\begin{array}{l}\text { Dammaranes (hydroxydammarenone, dammaradienol), ursanes } \\
\text { (ursonic acid, ursonaldehyde) }\end{array}$ \\
\hline Sapindales & Anacardiaceae & Pistacia (mastic) & $\begin{array}{l}\text { Euphanes (masticadienonic acid, isomasticadienonic acid), } \\
\text { dammaranes, oleanananes (oleanonic acid, moronic acid) }\end{array}$ \\
\hline Arecales & Arecaceae & Daemonorops (dragon’s blood) & Dracoresinotannol, dracorubin, dracorhodin, abietic acid \\
\hline
\end{tabular}

region, colophony presents the most intense feature with respect to the other resins, falling at about $1250 \mathrm{~cm}^{-1}$. In addition to all these described common frequencies, it is important to notice that sandarac and Manila copal show a recognizable, characteristic system of peaks mostly related to the conjugated double bonds occurring in the side chain of communic acid, which predominantly composed the highly cross-linked fraction of these resins. These sharp, narrow and moderately strong bands are positioned at $3080(\nu \mathrm{CH}$ from $\mathrm{C}=\mathrm{C}$ bonds, appearing very weak in Venetian turpentine and colophony), $1645(\nu \mathrm{C}=\mathrm{C})$ and 890 (out-of-plane bending of the exomethylene groups) $\mathrm{cm}^{-1}$. Furthermore, these two resins exhibit other well resolved, weak bands at 2730, 1410, $1330,1315,1030,795 \mathrm{~cm}^{-1}$.

In total reflection mode spectra (Figure 6), the most intense band over the MIR of all these substances is produced by $\mathrm{C}=\mathrm{O}$ groups of resinous acids, with the maximum falling from approximately 1730 to about $1715 \mathrm{~cm}^{-1}$ and the lineshape being characterized by a rapid, steep slope. As can be seen in the same figure, these groups give rise to the strongest and sharpest peak of the KK transformed spectra. Another very striking region corresponds to the $\nu \mathrm{CH}$ vibrations where the asymmetric $\mathrm{CH}_{3} / \mathrm{CH}_{2}$ modes produce an intense band maximum near $2985 \mathrm{~cm}^{-1}$ followed by a steep band slope. The weak symmetric $\mathrm{CH}_{3}$ stretching band, with the maximum being placed near $2880 \mathrm{~cm}^{-1}$, appears more resolved in Venetian turpentine and colophony with respect to sandarac and Manila copal which present the additional, sharp symmetric $\mathrm{CH}_{2}$ stretching band maximum at $2857 \mathrm{~cm}^{-1}$. Moderately strong $\delta \mathrm{CH}$ bands, all characterized by a rapid slope of the lineshape, present sharp maxima at around $1475 \mathrm{~cm}^{-1}$ and $1395 \mathrm{~cm}^{-1}$, in addition to which the $1455 \mathrm{~cm}^{-1}$ band maximum (due to $\mathrm{CH}_{3}$ groups) occurs in all resins with the exception of Venetian turpentine. This last further feature contributes to form the well-resolved doublet that is visible in the $1490-1420 \mathrm{~cm}^{-1}$ region of the KKT spectra. The C-O vibrations produce a significant medium-intensity band with the maximum falling from 1290 to $1280 \mathrm{~cm}^{-1}$ and gradually weaker bands with the maxima placed near 1190 and $1050 \mathrm{~cm}^{-1}$. On the other hand, the O$\mathrm{H}$ bands cannot be easily discerned in reflection mode. As previously reported, sandarac and Manila copal exhibit some characteristic additional features related to the presence of conjugated double bonds in their composition. In detail, the weak and well-defined band with the maximum at $3085 \mathrm{~cm}^{-1}$, then the weak-to-moderate band with the sharp maximum at $1650 \mathrm{~cm}^{-1}$, and finally the moderately strong and wellresolved band having the maximum positioned at $900 \mathrm{~cm}^{-1}$ as well as a very steep slope of the lineshape. The experimental wavenumber values corresponding to the maxima of the midIR total reflection mode bands, and the relative suggested assignment, are reported in Table 5.

As regards NIR range, all reflectance spectra (Figure 2(c)) are characterized by similar pattern except for Venetian turpentine which displays no features over the $4400-4000 \mathrm{~cm}^{-1}$ region (a flat, steady line is here visible). In this region, indeed, the other three resins exhibit sharp, well resolved $\nu_{\mathrm{a}}\left(\mathrm{CH}_{2}\right)+\delta\left(\mathrm{CH}_{2}\right)$ and $\nu_{\mathrm{s}}\left(\mathrm{CH}_{2}\right)+\delta\left(\mathrm{CH}_{2}\right)$ combination bands respectively found at 4325 and $4252 \mathrm{~cm}^{-1}$. Common to all resins are the first overtone bands from methylenic stretching at 5775 (asymmetric) and 5665 (symmetric) $\mathrm{cm}^{-1}$, then the weak and broad combination band of $\nu(\mathrm{OH})+\delta(\mathrm{OH})$ which is centered at around $5170 \mathrm{~cm}^{-1}$, and finally the poorly defined band near $4865 \mathrm{~cm}^{-1}$. Weak-to-moderate and well-defined bands are also found at 6120 and $4725 \mathrm{~cm}^{-1}$, respectively due to the first overtone of $\nu\left(\mathrm{CH}_{2}\right)$ cyclic and the combination of $\mathrm{C}-\mathrm{O}$ and $\mathrm{OH}$ stretching. However, these two features do not occur in colophony. Moreover, sandarac and Manila copal display an additional weak peak at 4615 which can be attributed to the combination of $v(\mathrm{C}-\mathrm{O})+v\left(\mathrm{CH}_{2}\right)[1]$.

Triterpenoid resins Triterpenoid resins consist of mixtures of triterpenoid molecules with mainly pentacyclic (ursanes, oleananes, lupanes and hopanes) and tetracyclic (dammaranes and lanostanes) skeletons. Table 4 reports the botanical origin and the kind of terpenoid compounds of the analyzed triterpenoid resins (i.e., mastic, dammar).

The mid-IR TR spectra of the two analyzed resins are characterized by the same band frequencies, with some slight differences appearing in the low-wavenumber peaks intensity (Figure 7). Moreover, the main fundamental frequencies are in common with the diterpenoid resins, resulting in extremely similar IR profiles which make it difficult to identify the different plant resins. The acquired spectra exhibit the most intense absorptions at 2945 (a saturated, less defined 
TABLE 5: Experimental wavenumber values corresponding to the maxima of the mid-IR total reflection mode bands of diterpenoid resins and their tentative assignment.

\begin{tabular}{|c|c|c|c|c|}
\hline \multicolumn{4}{|c|}{ Experimental wavenumbers $\left(\mathrm{cm}^{-1}\right)$} & \multirow[t]{2}{*}{ Band assignment } \\
\hline Sandarac & Manila copal & Colophony & Venetian turpentine & \\
\hline 3085 & 3085 & & & $v \mathrm{HC}=\mathrm{C}$ \\
\hline 2985 & 2985 & 2985 & 2985 & $v_{\text {as }} \mathrm{CH}_{3} / \mathrm{CH}_{2}$ \\
\hline 2880 & 2880 & 2880 & 2880 & $v_{\mathrm{s}} \mathrm{CH}_{3}$ \\
\hline 2857 & 2857 & & & $v_{\mathrm{s}} \mathrm{CH}_{2}$ \\
\hline 1720 & 1730 & 1730 & 1718 & $\nu \mathrm{C}=\mathrm{O}$ \\
\hline 1650 & 1650 & & & $\nu \mathrm{C}=\mathrm{C}$ \\
\hline 1475 & 1475 & 1475 & 1475 & $\delta \mathrm{CH}_{2}$ \\
\hline 1455 & 1455 & 1455 & & $\delta_{\mathrm{as}} \mathrm{CH}_{3}$ \\
\hline 1395 & 1395 & 1395 & 1395 & $\delta_{\mathrm{s}} \mathrm{CH}_{3}$ \\
\hline 1280 & 1280 & 1290 & 1290 & $\mathrm{C}-\mathrm{O}$ \\
\hline 1190 & 1190 & 1190 & 1190 & $\mathrm{C}-\mathrm{O}$ \\
\hline 1050 & 1050 & 1050 & 1050 & $\mathrm{C}-\mathrm{O}$ \\
\hline 900 & 900 & & & $\delta \mathrm{H}_{2} \mathrm{C}=\mathrm{C}$ \\
\hline
\end{tabular}

signal occurs in dammar) and $2872 \mathrm{~cm}^{-1}$, respectively due to asymmetric $\mathrm{CH}_{3} / \mathrm{CH}_{2}$ and symmetric $\mathrm{CH}_{3}$ stretches, and at $1705 \mathrm{~cm}^{-1}$, due to the $\mathrm{C}=\mathrm{O}$ stretching of the resinous acids. Further characteristic sharp, moderately strong peaks are produced by the $\mathrm{CH}$ bending vibrations at $1455\left(\mathrm{CH}_{3} / \mathrm{CH}_{2}\right.$ groups) and $1380\left(\mathrm{CH}_{3}\right.$ group) $\mathrm{cm}^{-1}$. On the other hand, the intensity of all the C-O vibrations falling in the 1300$900 \mathrm{~cm}^{-1}$ region appears low to very low. Another weak band, characterized by a quite broad shape, is due to the $\mathrm{O}-\mathrm{H}$ stretching vibration and is centered at around $3440 \mathrm{~cm}^{-1}$. Moreover, the presence of carbon-carbon double bonds in the cycling ring structure or in its side chains produces the weak bands positioned at 3070 ( $\nu \mathrm{CH}$ from $\mathrm{C}=\mathrm{C}$ bonds) and $1645(\nu \mathrm{C}=\mathrm{C}) \mathrm{cm}^{-1}$, and the peak at $890 \mathrm{~cm}^{-1}$ (out-ofplane bending of the exomethylene groups) which appears sharp and weak-to-moderate in dammar resin. Differently from diterpenoid resins, mastic and dammar do not clearly show the $\mathrm{O}-\mathrm{H}$ vibrations of dimerized carboxyl groups in the region of $2700-2500 \mathrm{~cm}^{-1}$.

The MIR total reflection mode spectra of mastic and dammar (Figure 7) exhibit four recognizable, strong bands each of which is characterized by very steep slope and sharp, well-resolved maximum. Their band maxima fall at about $2980\left(\nu_{\mathrm{as}} \mathrm{CH}_{3} / \mathrm{CH}_{2}\right), 1715(\nu \mathrm{C}=\mathrm{O}), 1475\left(\delta \mathrm{CH}_{3} / \mathrm{CH}_{2}\right)$ and $1392\left(\delta \mathrm{CH}_{3}\right) \mathrm{cm}^{-1}$. It should be noticed that the carbonyl stretching vibration produces another well-defined, weak band maximum at about $1735 \mathrm{~cm}^{-1}$ that can be ascribed to oxidation products (ketones, esters, lactones) [32] whose formation could have occurred during the bulk sample preparation. This feature gives rise to a slight asymmetry toward higher wavenumbers of the $\mathrm{C}=\mathrm{O}$ band in the corresponding KK transformed spectra (Figure 7), which is not observed in TR mode. Other weak and narrow band maxima are found at $2880 \mathrm{~cm}^{-1}\left(\nu_{\mathrm{s}} \mathrm{CH}_{3}\right)$ and over the $\mathrm{C}-\mathrm{O}$ vibrations region 1300 to $900 \mathrm{~cm}^{-1}$, whereas the weak-to-moderate $\delta \mathrm{H}_{2} \mathrm{C}=\mathrm{C}$ band with the lineshape having a rapid slope and the maximum being positioned at $896 \mathrm{~cm}^{-1}$ clearly occurs only in dammar
TABLE 6: Experimental wavenumber values corresponding to the maxima of the mid-IR total reflection mode bands of triterpenoid resins and their tentative assignment.

\begin{tabular}{lcc}
\hline \multicolumn{2}{c}{$\begin{array}{c}\text { Experimental } \\
\text { wavenumbers }\left(\mathbf{c m}^{-1}\right)\end{array}$} & Band assignment \\
\hline Mastic & Dammar & \\
3500 & 3500 & $\nu \mathrm{OH}$ \\
2988 & 2978 & $\nu_{\text {as }} \mathrm{CH}_{3} / \mathrm{CH}_{2}$ \\
2880 & 2880 & $\nu_{\mathrm{s}} \mathrm{CH}_{3}$ \\
1737 & 1731 & $\nu \mathrm{C}=\mathrm{O}($ ketones \\
& & esters, lactones $)$ \\
1715 & 1715 & $\nu \mathrm{C}=\mathrm{O}($ acids $)$ \\
1475 & 1475 & $\delta \mathrm{CH} / \mathrm{CH} H_{2}$ \\
1392 & 1392 & $\delta \mathrm{CH} 3$ \\
1270 & 1270 & $\mathrm{C}-\mathrm{O}$ \\
1207 & 1207 & $\mathrm{C}-\mathrm{O}$ \\
1116 & 1116 & $\mathrm{C}-\mathrm{O}$ \\
1085 & 1094 & $\mathrm{C}-\mathrm{O}$ \\
1050 & 1055 & $\mathrm{C}-\mathrm{O}$ \\
& 896 & $\delta \mathrm{H}_{2} \mathrm{C}=\mathrm{C}$ \\
\hline
\end{tabular}

resin. However, the other bands due to the carbon-carbon double bonds vibrations do not appear in reflection mode. The only broad band over the mid-IR range is produced by the $\nu \mathrm{O}-\mathrm{H}$ vibrations and is characterized by a slight slope of the lineshape and a maximum falling near $3500 \mathrm{~cm}^{-1}$; this band does not clearly occur though after the KK correction. The experimental wavenumber values corresponding to the maxima of the mid-IR total reflection mode bands, and the relative suggested assignment, are given in Table 6 .

The NIR total reflection mode spectra display the first overtone bands of asymmetric and symmetric $\mathrm{CH}_{3} / \mathrm{CH}_{2}$ stretches, respectively near 5800 and $5760 \mathrm{~cm}^{-1}$, as predominant over this spectral region. Moreover, the weak first 


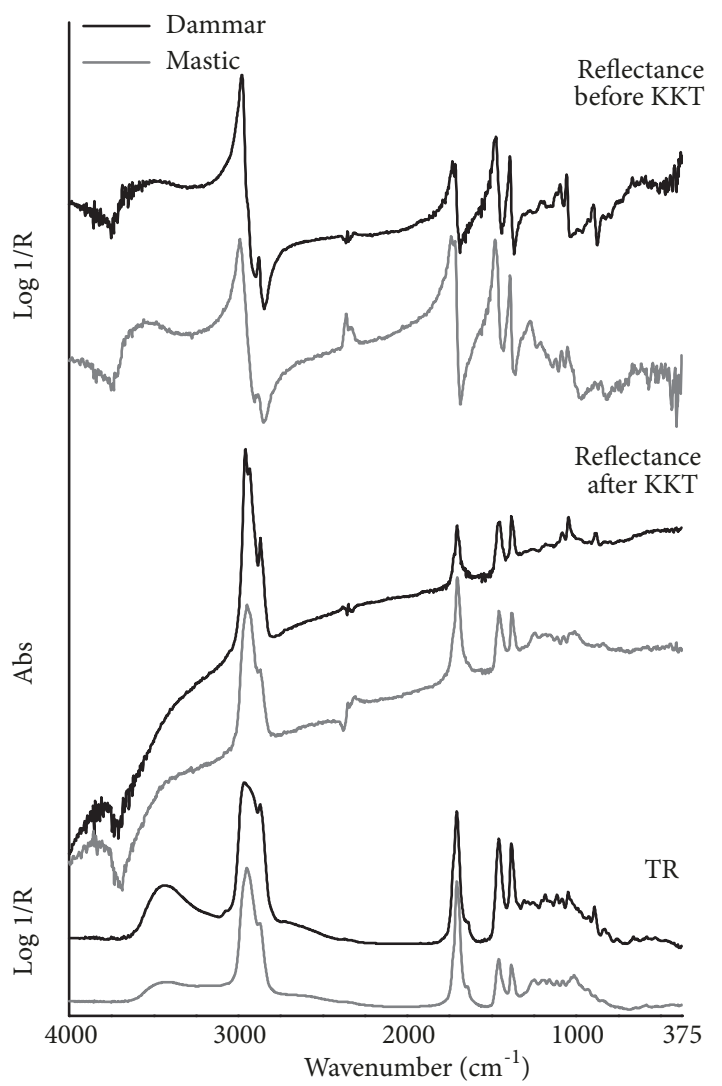

FIGURE 7: FTIR spectra in the mid-infrared region of the studied triterpenoid resins (black line: dammar, gray line: mastic) using different analysis modes. From top to bottom: total reflection mode before the KKT correction, total reflection mode after the KKT correction, and transflection mode.

overtone band of the $\nu \mathrm{CH}_{2}$ cyclic is found at $6100 \mathrm{~cm}^{-1}$ in dammar resin, while it is not clearly visible in mastic because of its marked spectral noise. In addition, less pronounced combination bands occur near $5180(\nu \mathrm{OH}+\delta \mathrm{OH})$ and $4850(\nu \mathrm{C}-\mathrm{O}+\nu \mathrm{OH}) \mathrm{cm}^{-1}$. It is worth noting that the $4400-4000 \mathrm{~cm}^{-1}$ region, where the combination bands of $\mathrm{CH}$ stretching and bending vibrations typically occur [1], does not show any features (a flat, steady line is here visible, as found in Venetian turpentine). The NIR total reflection mode spectra are reported in Figure 2(d).

Not (Exclusively) Terpenoid-Based Resins Among those resins that are not composed only of terpenes, shellac and dragon's blood have been playing a prominent role in the field of Cultural Heritage. Shellac, derived from secretions of the lac beetle and widely used in protective coatings for wooden surfaces, paintings, metal artworks and many other objects, is a complex mixture made of mono- and polyesters of hydroxyaliphatic and sesquiterpene acids whereas dragon's blood (botanical origin and chemical composition are reported in Table 4) has been mainly used as a coloring matter in paint, enhancing the color of precious stones and glass, marble and the wood for violins [35].

In TR mode (Figure 8), the MIR spectrum of shellac shows the intense, sharp $\mathrm{CH}$ stretching bands at 2945

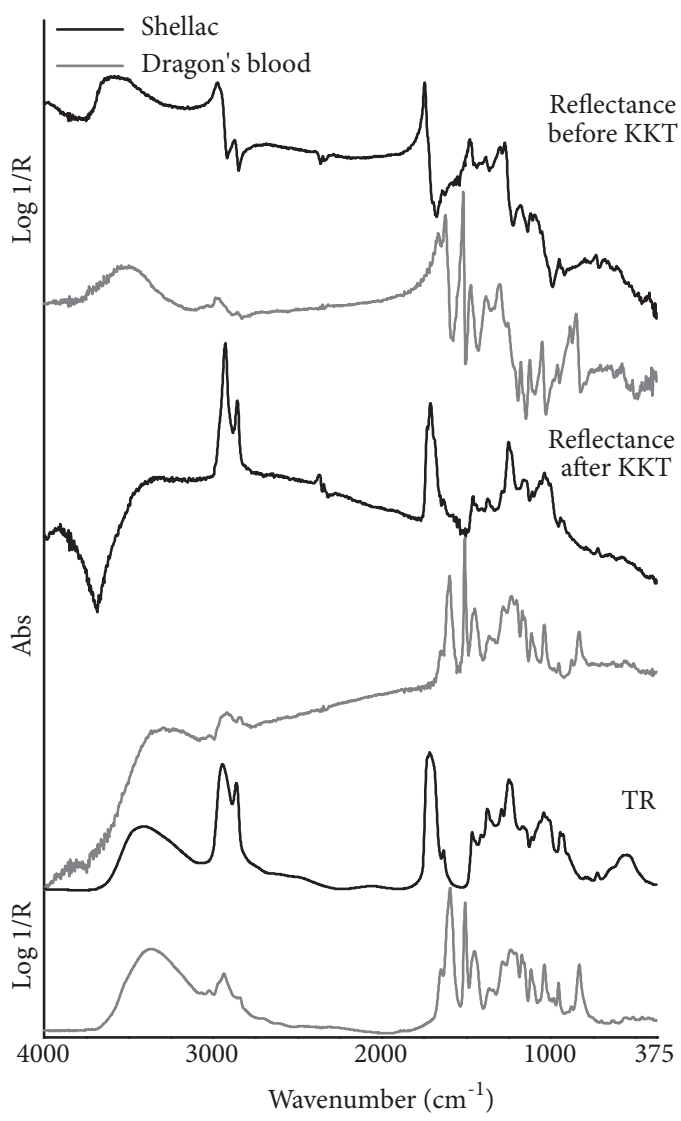

FIGURE 8: FTIR spectra in the mid-infrared region of the studied not (exclusively) terpenoid-based resins (black line: shellac, gray line: dragon's blood) using different analysis modes. From top to bottom: total reflection mode before the KKT correction, total reflection mode after the KKT correction, and transflection mode.

(asymmetric) and 2860 (symmetric) $\mathrm{cm}^{-1}$ and the strong, poorly resolved doublets at $1730-1715$ and $1245-1235 \mathrm{~cm}^{-1}$ due to the stretching of the carbonyl (from acids and esters) and the C-O groups, respectively. Medium-intensity bands are produced by $\mathrm{CH}$ bending vibrations lying at $1375\left(\mathrm{CH}_{3}\right.$ asymmetric mode $)$ and $1465 \mathrm{~cm}^{-1}\left(\mathrm{CH}_{2}\right.$ in-plane bending or scissoring), with the weak $\mathrm{CH}_{3}$ asymmetric mode shoulder occurring at $1448 \mathrm{~cm}^{-1}$, and by $\mathrm{C}-\mathrm{O}$ stretching vibrations from approximately 1200 to about $1000 \mathrm{~cm}^{-1}$. A similar intensity characterizes the broad $\mathrm{O}-\mathrm{H}$ stretching band centered at $3420 \mathrm{~cm}^{-1}$ and the characteristic doublet at $945-930 \mathrm{~cm}^{-1}$. Moreover, the carbon-carbon stretching vibrations produce a weak-to-moderate and sharp olefinic band at $1636 \mathrm{~cm}^{-1}$ as well as a weak and well-defined C-C band at $725 \mathrm{~cm}^{-1}$ from partially crystalline long-chain hydrocarbons. On the other hand, the spectrum of dragon's blood is characterized by many sharp, well-resolved bands in the fingerprint region. The strongest peaks over this region are produced by the stretching vibration of aromatic carbon-carbon double bonds at 1596 and $1507 \mathrm{~cm}^{-1}$, with the band at $1450 \mathrm{~cm}^{-1}$ appearing less pronounced [25]. Bands of medium intensity are found at $1650 \mathrm{~cm}^{-1}$, due to the $\mathrm{C}=\mathrm{C}$ stretching mode, in the region 


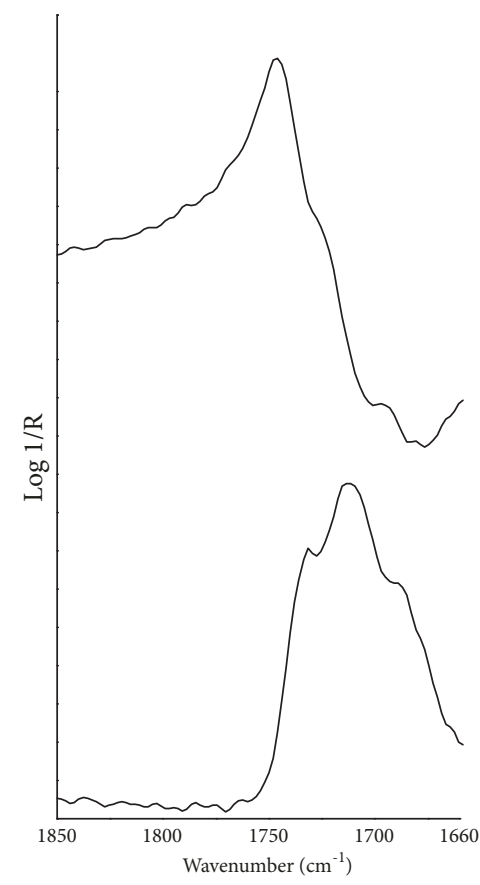

(a)

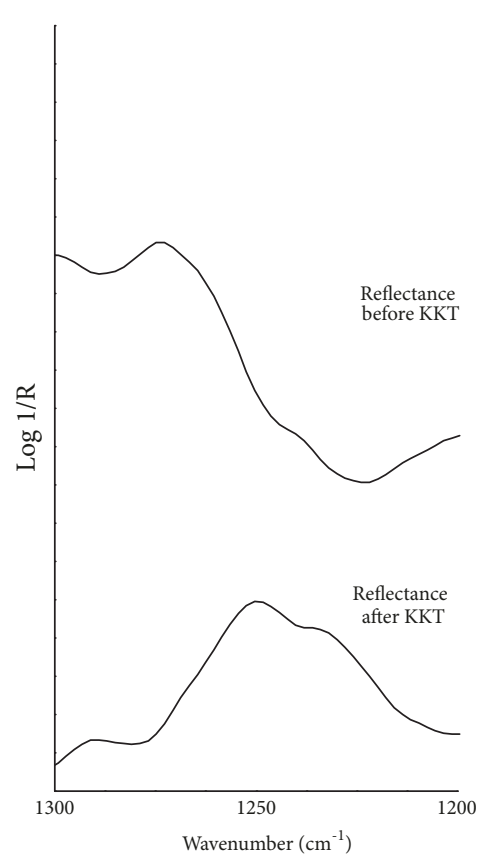

(b)

FIGURE 9: FTIR total reflection mode spectra of shellac before and after the KKT correction in the regions of (a) C=O stretching bands and (b) C-O stretching bands.

of the C-O stretching vibrations at 1235-1210, 1172-1160 and $1115 \mathrm{~cm}^{-1}$, and, finally, from approximately 1000 to about $800 \mathrm{~cm}^{-1}$ where in-plane aromatic $\mathrm{CH}$ bending vibrations occur at $1040 \mathrm{~cm}^{-1}$ and out-of-plane aromatic and olefinic $\mathrm{CH}$ bending vibrations appear at 955 and $830 \mathrm{~cm}^{-1}$ [36]. Toward the high-wavenumber region, a moderately strong, broad $\mathrm{O}-\mathrm{H}$ stretching band lies near $3370 \mathrm{~cm}^{-1}$ while $\mathrm{CH}$ stretching vibrations produce several weak bands at 3025 (aromatic and olefinic groups), $2865\left(\mathrm{CH}_{3}\right.$ groups) and $2840\left(\mathrm{CH}_{2}\right.$ groups $\mathrm{cm}^{-1}$ and a weak-to-moderate band at $2935 \mathrm{~cm}^{-1}\left(\mathrm{CH}_{2}\right.$ groups) with the shoulder of $\mathrm{CH}_{3}$ groups positioning at $2965 \mathrm{~cm}^{-1}$.

In the total reflection mode spectrum of shellac (Figure 8), the most intense features over the MIR range appear with a steep slope of the lineshape and sharp band maxima that fall at 2970 and $2873(\nu \mathrm{CH}), 1747(\nu \mathrm{C}=\mathrm{O})$ and 1273 $(\nu \mathrm{C}-\mathrm{O}) \mathrm{cm}^{-1}$. It is worth noting that both $\mathrm{C}=\mathrm{O}$ and $\mathrm{C}-$ $\mathrm{O}$ stretching bands present a slight slope variation along the lineshape, which is responsible for the formation of the $1731-1712$ and $1250-1235 \mathrm{~cm}^{-1}$ doublets after the KK transformation, respectively (Figure 9). Weak-to-moderate bands are all characterized by a slighter lineshape slope with the less resolved maxima falling near 1470, 1385, 1180, 950930 and $733 \mathrm{~cm}^{-1}$. Their corresponding peak assignments are reported in Table 7 . The $\nu \mathrm{C}-\mathrm{O}$ bands in the $1200-$ $1000 \mathrm{~cm}^{-1}$ region are partially well resolved and partially defined only by slope changes of the lineshape, as confirmed observing the KKT spectrum. The $\nu \mathrm{O}-\mathrm{H}$ band differs from all others because of its broad maximum, centered at around $3570 \mathrm{~cm}^{-1}$, and its slightly pronounced slope which extends from approximately 3500 to about $3200 \mathrm{~cm}^{-1}$. However, in correspondence of this high wavenumbers region the $\mathrm{KK}$ algorithm produces a flat line which is preceded by a deep falling as artefact. The total reflection mode spectrum of dragon's blood (Figure 8) presents a peculiar, distinctive fingerprint region where most of the bands have a well-resolved lineshape with steep to very steep slopes and sharp maxima (see Table 7 for the wavenumber values). As expected, the KK spectrum has the same profile of the TR one whose bands and relative assignment has been already accurately described in the paragraph above. Observing the mid-IR region over the $2000 \mathrm{~cm}^{-1}$, the medium-intensity $\mathrm{O}-\mathrm{H}$ stretching band exhibits a wide maximum near $3500 \mathrm{~cm}^{-1}$ and a characteristic slightly pronounced slope, while the $\mathrm{CH}$ stretching vibrations produce weak-to-moderate bands with the lineshape being characterized by a few slope variations which give rise to $\mathrm{CH}_{3} / \mathrm{CH}_{2}$ overlapping bands after the application of the KK transformations. The detailed experimental wavenumber values of both shellac and dragon's blood, and the relative suggested assignment, are reported in Table 7.

As regards NIR region, the reflectance spectra of shellac and dragon's blood (Figure 2(e)) display a few common bands positioned at $5778 \mathrm{~cm}^{-1}$, due to the first overtone of asymmetric $\mathrm{CH}_{2}$ stretching vibration, and near 5200, 4800 , and $4650 \mathrm{~cm}^{-1}$ which are attributed respectively to $\nu(\mathrm{OH})+\delta(\mathrm{OH}), \nu(\mathrm{C}-\mathrm{O})+\nu(\mathrm{OH})$ and $\nu(\mathrm{C}-\mathrm{O})+\nu\left(\mathrm{CH}_{2}\right)$ combination bands. It should be noted that the described $v(\mathrm{C}$ $\mathrm{O})+\nu\left(\mathrm{CH}_{2}\right)$ band appears more intense and better resolved in dragon's blood compared to shellac, because of the likely additional contribution of the aromatic $\nu(\mathrm{CH})+\nu(\mathrm{CC})$ 
TABLE 7: Experimental wavenumber values corresponding to the maxima of the mid-IR total reflection mode bands of not (exclusively) terpenoid-based resins and their tentative assignment.

\begin{tabular}{|c|c|}
\hline $\begin{array}{l}\text { Experimental } \\
\text { wavenumbers }\left(\mathrm{cm}^{-1}\right)\end{array}$ & Band assignment \\
\hline \multicolumn{2}{|l|}{ Shellac } \\
\hline 3570 & $\nu \mathrm{OH}$ \\
\hline 2970 & $v_{\mathrm{as}} \mathrm{CH}$ \\
\hline 2873 & $v_{\mathrm{s}} \mathrm{CH}$ \\
\hline 1747 & $\nu \mathrm{C}=\mathrm{O}$ \\
\hline 1470 & In-plane $\delta \mathrm{CH}_{2}$ \\
\hline 1385 & $\delta_{\mathrm{as}} \mathrm{CH}_{3}$ \\
\hline 1273 & $\nu \mathrm{C}-\mathrm{O}$ \\
\hline 1180 & $\nu \mathrm{C}-\mathrm{O}$ \\
\hline 1120 & $\nu \mathrm{C}-\mathrm{O}$ \\
\hline 1095 & $\nu \mathrm{C}-\mathrm{O}$ \\
\hline 1075 & $\nu \mathrm{C}-\mathrm{O}$ \\
\hline 1055 & $\nu \mathrm{C}-\mathrm{O}$ \\
\hline 1015 & $\nu \mathrm{C}-\mathrm{O}$ \\
\hline 1030 & $v \mathrm{C}-\mathrm{O}$ \\
\hline \multicolumn{2}{|l|}{$950-930$} \\
\hline 733 & $\nu \mathrm{C}-\mathrm{C}$ \\
\hline \multicolumn{2}{|l|}{ Dragon's blood } \\
\hline 3500 & $\nu \mathrm{OH}$ \\
\hline 3030 & $\nu \mathrm{CH}$ (aromatic, olefinic) \\
\hline 2963 & $v_{\mathrm{as}} \mathrm{CH}$ \\
\hline 2855 & $v_{\mathrm{s}} \mathrm{CH}$ \\
\hline 1665 & $\nu \mathrm{C}=\mathrm{C}, \nu \mathrm{C}=\mathrm{O}$ \\
\hline 1623 & $\nu \mathrm{C}=\mathrm{C}$ (aromatic) \\
\hline 1520 & $\nu \mathrm{C}=\mathrm{C}$ (aromatic) \\
\hline 1473 & $\nu \mathrm{C}=\mathrm{C}$ (aromatic) \\
\hline \multicolumn{2}{|l|}{1300} \\
\hline 1255 & $\nu \mathrm{C}-\mathrm{O}$ \\
\hline 1218 & $\nu \mathrm{C}-\mathrm{O}$ \\
\hline 1178 & $\nu \mathrm{C}-\mathrm{O}$ \\
\hline 1164 & $\nu \mathrm{C}-\mathrm{O}$ \\
\hline 1123 & $\nu \mathrm{C}-\mathrm{O}$ \\
\hline 1052 & In-plane $\delta \mathrm{CH}$ (aromatic) \\
\hline 960 & $\begin{array}{l}\text { Out-of-plane } \delta \mathrm{CH} \\
\text { (aromatic, olefinic) }\end{array}$ \\
\hline 885 & $\begin{array}{l}\text { Out-of-plane } \delta \mathrm{CH} \\
\text { (aromatic, olefinic) }\end{array}$ \\
\hline 850 & $\begin{array}{l}\text { Out-of-plane } \delta \mathrm{CH} \\
\text { (aromatic, olefinic) }\end{array}$ \\
\hline
\end{tabular}

combination band. Other common features are found in the 4500-4000 region, where the $v_{\text {as }}\left(\mathrm{CH}_{2}\right)+\delta\left(\mathrm{CH}_{2}\right)$ and $v_{s}\left(\mathrm{CH}_{2}\right)+\delta\left(\mathrm{CH}_{2}\right)$ combination bands lie respectively at 4342 and $4263 \mathrm{~cm}^{-1}$. These bands are strong, sharp, and well defined in the spectrum of shellac because of its characteristic aliphatic chains while they appear broad, very weak in the spectrum of dragon's blood. Moreover, in this spectral portion shellac shows another signal at $4040 \mathrm{~cm}^{-1}$, which is due to the third overtone of the CC bending vibration. Conversely, additional high-wavenumber bands linked to the presence of aromatic structures characterize the dragon's blood resin at about 5950 and $6900 \mathrm{~cm}^{-1}$, respectively attributed to the first overtone of aromatic $\mathrm{CH}$ stretching vibration and to the dual contribution of the first overtone of $\nu(\mathrm{OH})$ and the aromatic $\mathrm{CH}$ combination. Finally, it can be noticed that the first overtone band of $\nu\left(\mathrm{CH}_{2}\right)$ at $5668 \mathrm{~cm}^{-1}$ appears well defined only in the spectrum of dragon's blood, whereas the marked noise toward the high wavenumbers does not allow us to discern it in the shellac resin. It is important to point out that the interpretation of the NIR signals of dragon's blood has been based on vibration charts [30], because no band assignment has occurred in literature using the infrared spectroscopy technique.

\section{Conclusions}

The aim of the present paper is to provide a valuable analytical tool to conservators and scientists for a complete comprehension of infrared spectra acquired in total reflection mode by means of portable noncontact FTIR spectrometers. The knowledge of the reflectance spectral behavior in the mid and near-infrared region of pure standards represents, in fact, the first necessary step for subsequently tackling the more complex interpretation of aged substances, mixtures (e.g., varnishes) or layered systems occurring in real cases. Understanding when specific data-processing algorithms can be applied with accurate results represents another important issue here discussed.

In this work, we present FTIR total reflection mode spectra of sixteen pure, nonaged natural organic materials widely spread in works of art. The spectral analysis of absorption bands acquired in transflection mode has been significant, firstly, to approach the study of distorted reflection bands and, then, to evaluate the applicability of KK correction in the MIR region. Moreover, a visual comparison between reflection and absorption bands is useful to make the different spectral behavior understandable.

The study mainly focuses on the mid-IR region (4000$375 \mathrm{~cm}^{-1}$ ) where the specular reflection contribution appears predominant giving rise to a derivative-shaped spectral profile. According to low absorption coefficient materials, Reststrahlen bands do not occur. A novel, tentative approach to the discussion of specular reflectance bands compared to absorbance ones is here provided. The good wavenumber and lineshape correspondence between KK corrected and transflection bands allowed us to conclude that an accurate result from KK algorithm has been achieved for the sample references, thus confirming the specular reflection as the main collected contribute of the total reflection mode spectra in the mid-IR region. Then, the work tackles the interpretation of combination and overtone bands in the near-IR range $\left(7500-4000 \mathrm{~cm}^{-1}\right)$, where the diffuse reflection phenomenon is dominant.

Despite the possible limitation represented by artwork superficial conditions, which necessarily have to be evaluated 
case by case, we consider our results promising for their application in the Cultural Heritage field.

\section{Data Availability}

The data used to support the findings of this study are included within the article.

\section{Disclosure}

This research received no specific grant from any funding agency in the public, commercial, or not-for-profit sectors.

\section{Conflicts of Interest}

The authors declare that there are no conflicts of interest regarding the publication of this paper.

\section{Acknowledgments}

The authors wish to thank Prof. Claudio Canevari and Dr. Maduka Weththimuni for the support in the choice and preparation of the reference samples.

\section{References}

[1] M. Vagnini, C. Miliani, L. Cartechini, P. Rocchi, B. G. Brunetti, and A. Sgamellotti, "FT-NIR spectroscopy for non-invasive identification of natural polymers and resins in easel paintings," Analytical and Bioanalytical Chemistry, vol. 395, no. 7, pp. 21072118, 2009.

[2] C. Ricci, C. Miliani, B. G. Brunetti, and A. Sgamellotti, "Noninvasive identification of surface materials on marble artifacts with fiber optic mid-FTIR reflectance spectroscopy," Talanta, vol. 69, no. 5, pp. 1221-1226, 2006.

[3] B. Brunetti, C. Miliani, F. Rosi et al., "Non-invasive Investigations of Paintings by Portable Instrumentation: The MOLAB Experience," Topics in Current Chemistry, vol. 374, no. 1, 2016.

[4] J. Echard, "In situ multi-element analyses by energy-dispersive X-ray fluorescence on varnishes of historical violins," Spectrochimica Acta Part B: Atomic Spectroscopy, vol. 59, no. 10-11, pp. 1663-1667, 2004.

[5] G. Valentina Fichera, M. Albano, G. Fiocco et al., "Innovative Monitoring Plan for the Preventive Conservation of Historical Musical Instruments," Studies in Conservation, vol. 63, no. sup1, pp. 351-354, 2018.

[6] C. Miliani, F. Rosi, A. Daveri, and B. G. Brunetti, "Reflection infrared spectroscopy for the non-invasive in situ study of artists' pigments," Applied Physics A: Materials Science \& Processing, vol. 106, no. 2, pp. 295-307, 2012.

[7] F. Casadio and L. Toniolo, "The analysis of polychrome works of art: 40 years of infrared spectroscopic investigations," Journal of Cultural Heritage, vol. 2, no. 1, pp. 71-78, 2001.

[8] G. Fiocco, T. Rovetta, M. Gulmini, A. Piccirillo, M. Licchelli, and M. Malagodi, "Spectroscopic Analysis to Characterize Finishing Treatments of Ancient Bowed String Instruments," Applied Spectroscopy, vol. 71, no. 11, pp. 2477-2487, 2017.

[9] F. Rosi, A. Daveri, C. Miliani et al., "Non-invasive identification of organic materials in wall paintings by fiber optic reflectance infrared spectroscopy: A statistical multivariate approach," Analytical and Bioanalytical Chemistry, vol. 395, no. 7, pp. 20972106, 2009.

[10] T. Poli, E. Alice, and O. Chiantore, "Surface Finishes and Materials: Fiber-Optic Reflectance Spectroscopy (FORS) Problems in Cultural Heritage Diagnostics," in e-Preservation Science, vol. 6, pp. 174-179, 2009.

[11] T. Poli, O. Chiantore, M. Nervo, and A. Piccirillo, "Mid-IR fiber-optic reflectance spectroscopy for identifying the finish on wooden furniture," Analytical and Bioanalytical Chemistry, vol. 400, no. 4, pp. 1161-1171, 2011.

[12] F. Rosi, A. Daveri, P. Moretti, B. G. Brunetti, and C. Miliani, "Interpretation of mid and near-infrared reflection properties of synthetic polymer paints for the non-invasive assessment of binding media in twentieth-century pictorial artworks," Microchemical Journal, vol. 124, pp. 898-908, 2016.

[13] C. Daher, V. Pimenta, and L. Bellot-Gurlet, "Towards a non-invasive quantitative analysis of the organic components in museum objects varnishes by vibrational spectroscopies: Methodological approach," Talanta, vol. 129, pp. 336-345, 2014.

[14] D. Saviello, L. Toniolo, S. Goidanich, and F. Casadio, "Noninvasive identification of plastic materials in museum collections with portable FTIR reflectance spectroscopy: Reference database and practical applications," Microchemical Journal, vol. 124, pp. 868-877, 2016.

[15] M. Fabbri, M. Picollo, S. Porcinai, and M. Bacci, "Mid-Infrared Fiber-Optics Reflectance Spectroscopy: A Noninvasive Technique for Remote Analysis of Painted Layers. Part II: Statistical Analysis of Spectra," Applied Spectroscopy, vol. 55, no. 4, pp. 428-433, 2016.

[16] P. R. Griffiths and J. A. De Haseth, "Fourier Transform Infrared Spectrometry: Second Edition," Fourier Transform Infrared Spectrometry: Second Edition, pp. 1-529, 2006.

[17] M. Fabbri, M. Picollo, S. Porcinai, and M. Bacci, "Mid-infrared fiber-optics reflectance spectroscopy: A noninvasive technique for remote analysis of painted layers. Part II: Statistical analysis of spectra," Applied Spectroscopy, vol. 55, no. 4, pp. 428-433, 2001.

[18] M. Picollo, G. Bartolozzi, C. Cucci, M. Galeotti, V. Marchiafava, and B. Pizzo, "Comparative study of fourier transform infrared spectroscopy in transmission, attenuated total reflection, and total reflection modes for the analysis of plastics in the cultural heritage field," Applied Spectroscopy, vol. 68, no. 4, pp. 389-397, 2014.

[19] C. Miliani, F. Rosi, I. Borgia, P. Benedetti, B. G. Brunetti, and A. Sgamellotti, "Fiber-optic Fourier transform mid-infrared reflectance spectroscopy: A suitable technique for in Situ studies of mural paintings," Applied Spectroscopy, vol. 61, no. 3, pp. 293299, 2007.

[20] C. Invernizzi, G. V. Fichera, M. Licchelli, and M. Malagodi, "A non-invasive stratigraphic study by reflection FT-IR spectroscopy and UV-induced fluorescence technique: The case of historical violins," Microchemical Journal, vol. 138, pp. 273-281, 2018.

[21] C. Invernizzi, A. Daveri, M. Vagnini, and M. Malagodi, "Noninvasive identification of organic materials in historical stringed musical instruments by reflection infrared spectroscopy: a methodological approach," Analytical and Bioanalytical Chemistry, vol. 409, no. 13, pp. 3281-3288, 2017.

[22] M. P. Colombini and F. Modugno, Organic Mass Spectrometry in Art and Archaeology, John Wiley \& Sons, Ltd, Chichester, UK, 2009. 
[23] C. Invernizzi, A. Daveri, T. Rovetta et al., "A multi-analytical non-invasive approach to violin materials: The case of Antonio Stradivari “Hellier" (1679)," Microchemical Journal, vol. 124, pp. 743-750, 2016.

[24] C. Daher, C. Paris, A.-S. Le Hô, L. Bellot-Gurlet, and J.-P. Échard, "A joint use of Raman and infrared spectroscopies for the identification ofnatural organic media used in ancient varnishes," Journal of Raman Spectroscopy, vol. 41, no. 11, pp. 1494-1499, 2010.

[25] M. Koperska, T. Łojewski, and J. Łojewska, "Vibrational spectroscopy to study degradation of natural dyes. Assessment of oxygen-free cassette for safe exposition of artefacts," Analytical and Bioanalytical Chemistry, vol. 399, no. 9, pp. 3271-3283, 2011.

[26] J. J. Bischoff, M. R. Derrick, D. Stulik, and J. M. Landry, "Infrared Spectroscopy in Conservation," Journal of the American Institute for Conservation, vol. 40, no. 3, p. 268, 2001.

[27] R. K. Vincent and G. R. Hunt, "Infrared reflectance from mat surfaces," Applied Optics, vol. 7, no. 1, pp. 53-59, 1968.

[28] M. T. Doménech-Carbó, "Novel analytical methods for characterising binding media and protective coatings in artworks," Analytica Chimica Acta, vol. 621, no. 2, pp. 109-139, 2008.

[29] M. de Buergo and R. González, "Protective patinas applied on stony façades of historical buildings in the past," Construction and Building Materials, vol. 17, no. 2, pp. 83-89, 2003.

[30] J. Workman Jr. and L. Weyer, Practical Guide to Interpretive Near-Infrared Spectroscopy, CRC Press, 2007.

[31] S. Merk, A. Blume, and M. Riederer, "Phase behaviour and crystallinity of plant cuticular waxes studied by Fourier transform infrared spectroscopy," Planta, vol. 204, no. 1, pp. 44-53, 1998.

[32] D. Scalarone, M. Lazzari, and O. Chiantore, "Ageing behaviour and analytical pyrolysis characterisation of diterpenic resins used as art materials: Manila copal and sandarac," Journal of Analytical and Applied Pyrolysis, vol. 68-69, pp. 115-136, 2003.

[33] M. Größl, S. Harrison, I. Kaml, and E. Kenndler, "Characterisation of natural polysaccharides (plant gums) used as binding media for artistic and historic works by capillary zone electrophoresis," Journal of Chromatography A, vol. 1077, no. 1, pp. 80-89, 2005.

[34] T. Geiger and F. Michel, "Studies on the polysaccharide JunFunori used to consolidate Matt Paint," Studies in Conservation, vol. 50, no. 3, pp. 193-204, 2005.

[35] D. Gupta, B. Bleakley, and R. K. Gupta, "Dragon's blood: botany, chemistry and therapeutic uses," Journal of Ethnopharmacology, vol. 115, no. 3, pp. 361-380, 2007.

[36] B. Stuart, "Infrared Spectroscopy: Fundamentals and Applications," in Climate Change 2013 - The Physical Science Basis, 2014. 

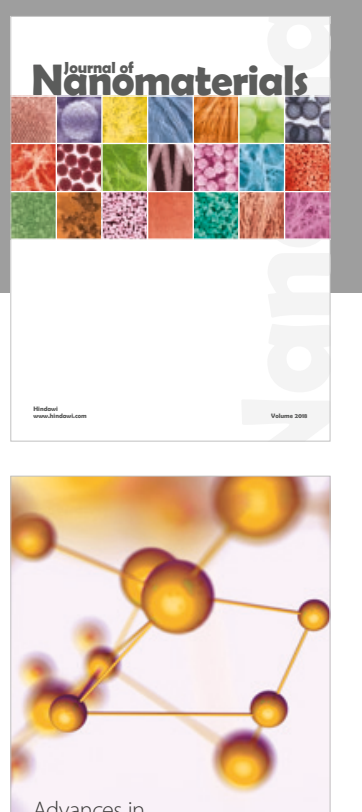

Physical Chemistry
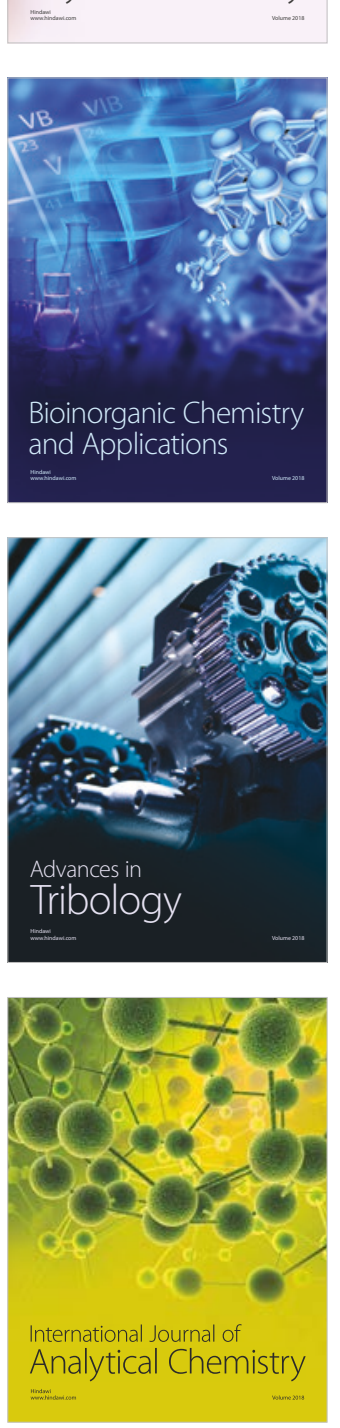

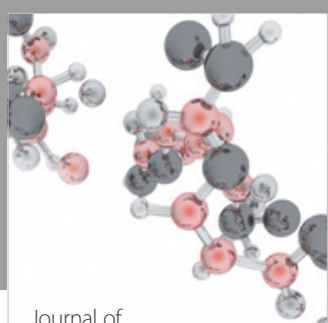

Analytical Methods

in Chemistry

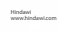

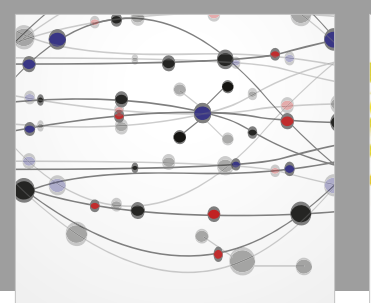

The Scientific World Journal

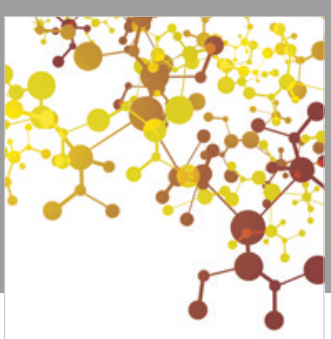

Journal of

Applied Chemistry
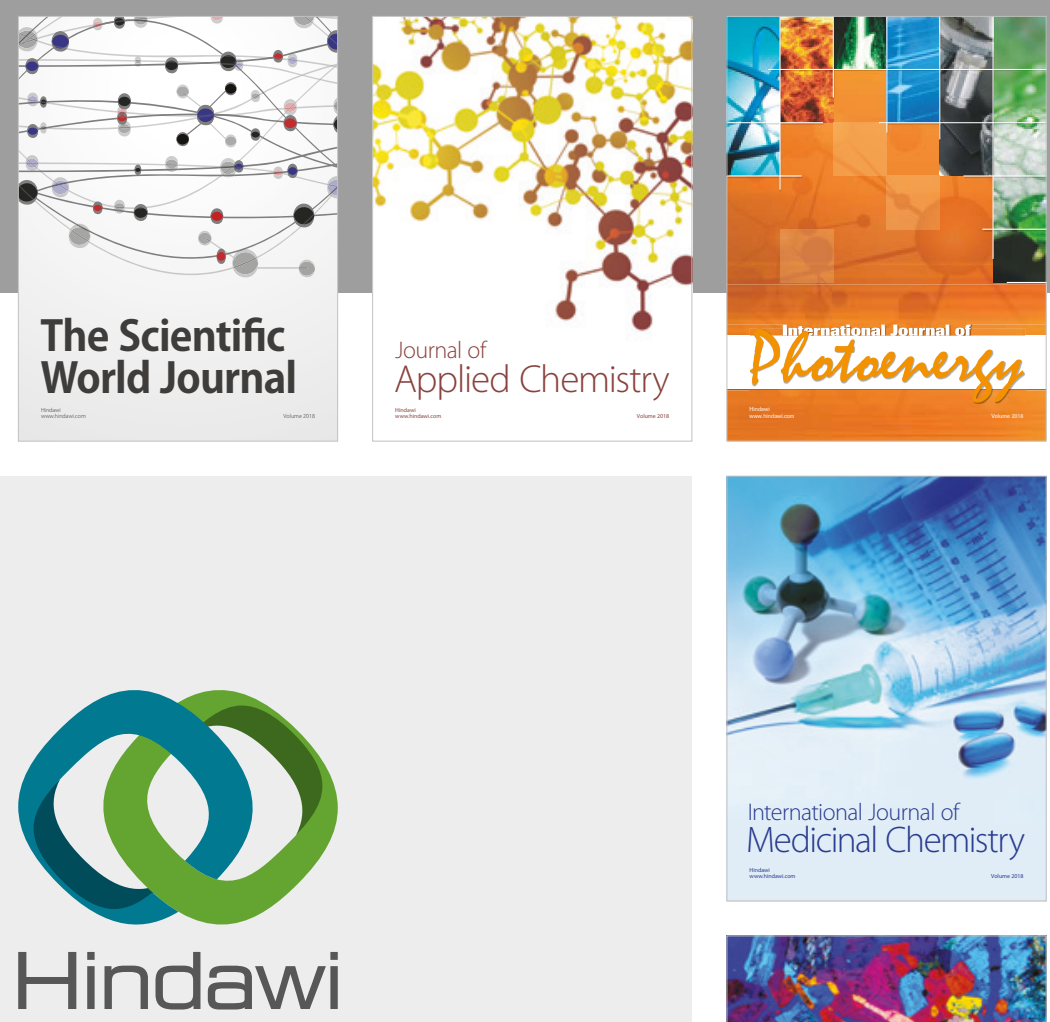

Submit your manuscripts at

www.hindawi.com
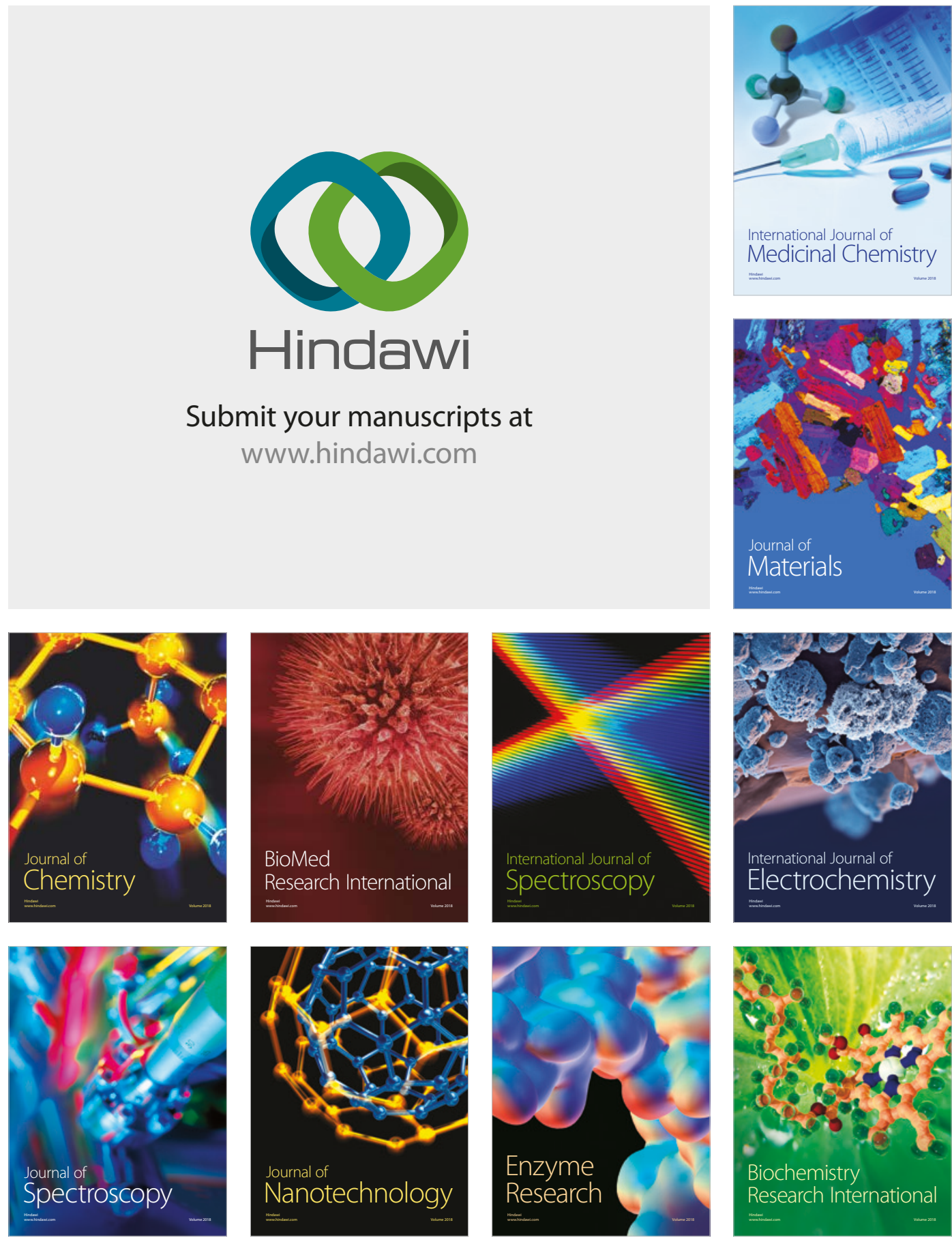
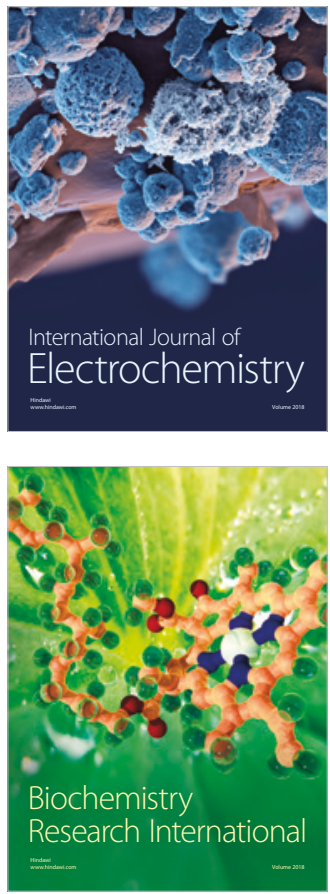